\title{
On Sub-ENSO Variability
}

\author{
Noel S. Keenlyside And Mojib Latif \\ Leibniz-Institut für Meereswissenschaften, Kiel, Germany \\ ANKE DÜRKOP \\ Institut für Geowissenschaften, Christian Albrechts Universität, Kiel, Germany
}

(Manuscript received 30 May 2006, in final form 27 October 2006)

\begin{abstract}
Multichannel singular spectrum analysis (MSSA) of surface zonal wind, sea surface temperature (SST), $20^{\circ}$ isotherm depth, and surface zonal current observations (between 1990 and 2004) identifies three coupled ocean-atmosphere modes of variability in the tropical Pacific: the El Niño-Southern Oscillation (ENSO), the annual cycle, and a mode with a 14-18-month period, which is referred to as sub-ENSO in this study. The sub-ENSO mode accounts for the near 18-month (near annual) variability prior to (following) the 1997/98 El Niño event. It was strongest during this El Niño event, with SST anomalies exceeding $1{ }^{\circ} \mathrm{C}$. Sub-ENSO peak SST anomalies are ENSO-like in structure and are associated with eastward propagating heat content variations. However, the SST anomalies are preceded by and in near quadrature with relatively strong remotely forced westward propagating zonal current variations, suggesting the sub-ENSO mode arises from the zonal-advective feedback.

The sub-ENSO mode is found to exist also in an intermediate complexity model (ICM) of the tropical Pacific. A heat budget analysis of the model's sub-ENSO mode shows it indeed arises from the zonaladvective feedback. In the model, both ENSO and sub-ENSO modes coexist, but there is a weak nonlinear interaction between them. Experiments also show that the observed changes in sub-ENSO's characteristics may be explained by changes in the relative importance of zonal and vertical advection SST tendencies.
\end{abstract}

\section{Introduction}

A lot of progress has been made over the last $20 \mathrm{yr}$ in our understanding of, and ability to observe, model, and predict, tropical Pacific climate variability (e.g., see McPhaden et al. 1998, and other articles of the J. Geophys. Res. TOGA special issue, 1998, Vol. 103, No. C7). The progress, however, has been primarily limited to ENSO and the annual cycle. While these phenomena explain the most variance, variability on other time scales is clearly evident (Fig. 1). Our lack of understanding of this variability is acutely felt in the poor skill of models to forecast this variability, as was for example the case during the early 1990s (e.g., Ji et al. 1996), and now appears to be the case as well.

Perhaps the most prominent examples of this poorly

Corresponding author address: Noel Keenlyside, LeibnizInstitut für Meereswissenschaften, Düsternbrooker Weg 20, Kiel D-24105, Germany.

E-mail: nkeenlyside@ifm-geomar.de

DOI: $10.1175 / J C L I 4199.1$

(C) 2007 American Meteorological Society understood variability are variations with periods between 1 and 2 yr. Obvious instances are the near 18month variations during the first half of the 1990s and the near-annual variations after the 1997/98 El Niño event (Fig. 1). While the positive SST anomalies of 1993 and 1994/95 have been interpreted as aborted El Niño events, inspection of observations shows that they do not fit the canonical ENSO picture, most strongly because there was little or no buildup of equatorial heat content anomalies prior to the events (e.g., Goddard and Graham 1997). Similarly, the near-annual variations that occurred at the end of 1998, 1999, and 2000 cannot be interpreted simply as changes in the annual cycle, most obviously because eastern Pacific SST anomalies are associated with local heat content variation and also with remote wind anomalies. Investigating whether variability on the 1-2-yr time scale represents another coupled ocean-atmosphere mode has been the motivation for several recent studies (Jin et al. 2003; Kang et al. 2004; Wu and Kirtman 2005), and forms the motivation for this work. 
(a) UWND (ms-1)

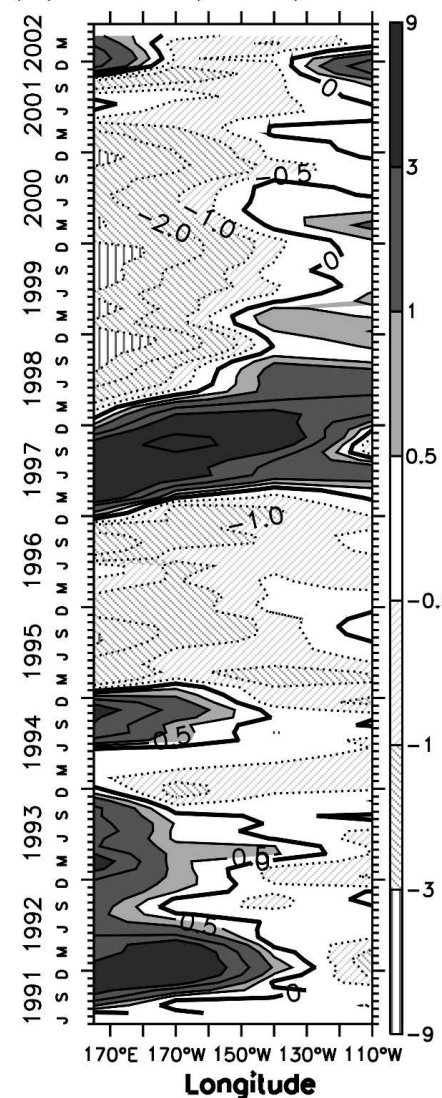

(b) $\mathbf{Z 2 0}(\mathrm{m})$

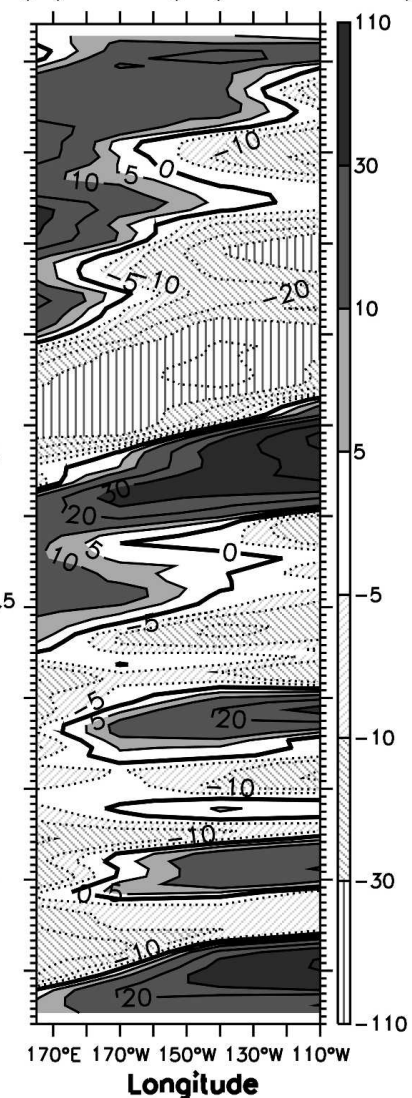

(c) SST $\left({ }^{\circ} \mathrm{C}\right)$

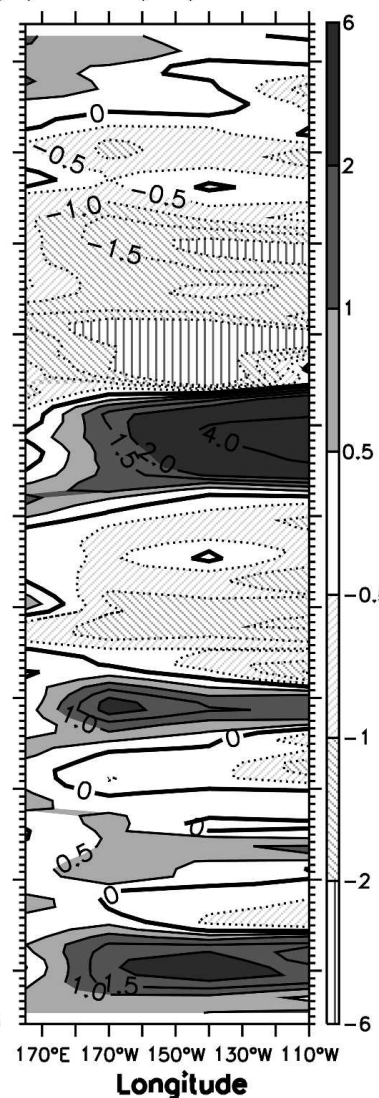

(d) $\mathrm{ZC}\left(\mathrm{cm} \mathrm{s}^{-1}\right)$

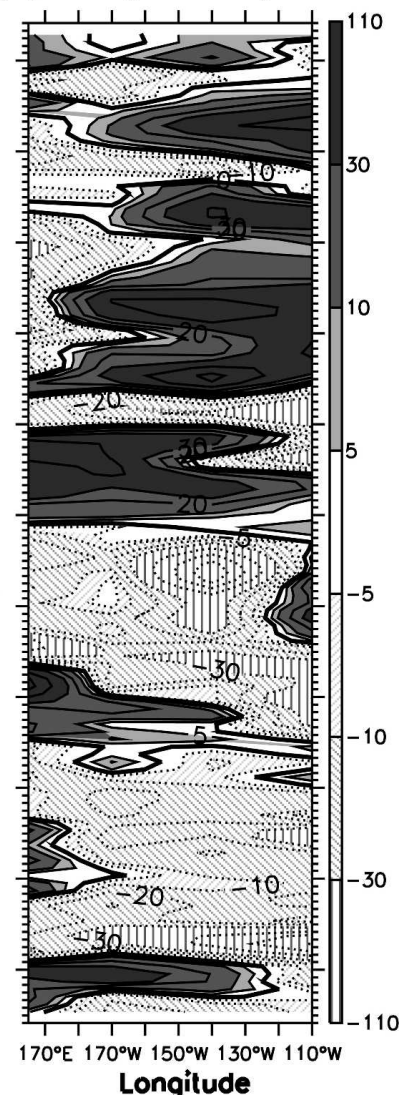

FIG. 1. Anomalies along the equator of observed (a) 10-m zonal wind, (b) $20^{\circ} \mathrm{C}$ isotherm depth, (c) SST, and (d) surface zonal currents for the period June 1991-May 2002. Data are from the TOGA/TAO array (McPhaden et al. 1998). They are smoothed here only for presentation with a three-point binomial filter in time. Dark shading (light shading with patterns) indicates positive (negative) anomalies. Contours are centered on 0 (solid dark) and are in (a) $\pm 0.5, \pm 1, \pm 2, \pm 3$, and \pm 6 ; (b) and (d) $\pm 5, \pm 10, \pm 20, \pm 30, \pm 50, \pm 70$, and \pm 90 ; and (c) $\pm 0.5, \pm 1, \pm 1.5, \pm 2$, and \pm 4 .

It has been argued that both the near-annual variability after the 1997/98 El Niño and the near 18-month variability prior to the event are explained by the $\mathrm{Pa}-$ cific basin mode destabilized by zonal advection of SST anomalies (Jin et al. 2003; Kang et al. 2004). The basin mode is the free solution of equatorial adjustment obtained from the long Kelvin and Rossby waves of the first baroclinic mode (Cane and Moore 1981), and it has a time scale of about 8 months for the Pacific. These authors argue that the longer period of the observed variability results from ocean-atmosphere coupling, via the zonal advection of SST anomalies, which gives the mode a hybrid nature. Furthermore, eigenanalysis of an intermediate complexity model (ICM) shows how background state changes may explain the mode's observed changes in period and zonal propagation characteristics (Kang et al. 2004).

Apart from a destabilized basin mode, numerous other possibilities may explain the near-annual variabil- ity. Stochastic forcing is one of the leading hypotheses for ENSO irregularity (e.g., Eckert and Latif 1997; Kleeman and Moore 1997). The near-annual variability could be part of the broad ENSO spectrum. A second possibility may be that it is an expression of changes in the characteristics of ENSO or the annual cycle. These could be induced by changes in the background state, as has been demonstrated by theoretical studies (An and Jin 2001; Federov and Philander 2001), or by nonlinear interactions between them. A third possibility is that it is due to one or more not-yet-identified coupled oceanatmosphere modes. Theoretical studies have proposed a wide spectrum of possible modes (Neelin et al. 1998), and others may exist. Coupled models, from complex to simple, also exhibit a wide range of variability (Latif et al. 2001).

The questions addressed by this work are as follows. First, does the 1-2-yr variability represent an independent mode of climate variability? Second, if so, what 
are its physics and do they correspond to any of the existing or already proposed modes of variability? Third and finally, what factors control its characteristics, in particular its activity? To achieve these goals multichannel singular spectrum analysis (MSSA) of observed Tropical Atmosphere Ocean/Triangle TransOcean Buoy Network (TAO/TRITON) data (McPhaden et al. 1998) is performed. MSSA is a statistical technique designed to identify oscillatory modes of variability in short noisy time series (Ghil et al. 2002). The analysis does indeed identify a third mode of variability. The mode is then further studied with an ICM to identify its physics, and the factors controlling its character.

The paper is structured as follows. In section 2 the data, analysis tools, and ICM used in this study are described. Section 3 presents the results of the MSSA of the TAO/TRITON data, and section 4 the results from the ICM simulations. Discussions and conclusions are presented in the last section.

\section{Data and methods}

A brief summary of the observational data, including their processing, the statistical techniques, and the intermediate complexity model used in this study are now given. Observations from two sources are analyzed: in situ observations from the TAO/TRITON array of moored buoys (McPhaden et al. 1998) and satellitederived surface currents from the Ocean Surface Currents Analyses-Real time (OSCAR) dataset (Bonjean and Lagerloef 2002). The main results of this work are obtained from observations of SST, $20^{\circ}$ isotherm depth, surface zonal winds, and $0-50-\mathrm{m}$ averaged surface zonal currents at the equator at $165^{\circ} \mathrm{E}, 170^{\circ} \mathrm{W}, 140^{\circ} \mathrm{W}$, and $110^{\circ} \mathrm{W}$ for the period June 1991 to September 2002. (Anomalies, from the annual cycle, of the data are shown in Fig. 1.) These locations were chosen since Acoustic Doppler Current Profiler (ADCP) measurements were available there for longer than $10 \mathrm{yr}$. The time period was determined by the availability of ADCP data at the study's commencement. No data from mechanical current meters were used in this study. Only monthly mean data are analyzed here. For the TAO/TRITON data, monthly means were created by averaging of daily means, after data gaps were filled by linear interpolation in time and in the zonal direction. While the averaging of zonal current measurements over the upper $50 \mathrm{~m}$ provides a proxy for the mixedlayer average zonal current, significant data gaps, particularly at the surface and in the east, may bias the average toward deeper values. The zonal current varia- tions of the climate modes studied here are primarily associated with the low-order baroclinic modes, and so we assume that these potential biases will not affect our results significantly.

In addition to this core set of data, observations of SST, $20^{\circ}$ isotherm depth, and surface zonal and meridional winds from the TAO/TRITON array at other locations on and off the equator are used to extend our analysis temporally and spatially. In this respect we also utilize the OSCAR current dataset, since TAO/ TRITON current data are confined to the equator. These currents are derived from gridded sea surface height (SSH), surface wind (W), and sea surface temperature (SST) data, using a combination of the geostrophic, Ekman-Stommel, and thermal-wind approximations, with a special treatment of the equatorial singularity (Bonjean and Lagerloef 2002). The data compare favorably with drifter data and in situ observations. Here we only analyze monthly mean OSCAR data that were calculated from the available pentad means.

The primary analysis technique applied here is MSSA, which is a generalization of singular spectrum analysis (SSA). Both SSA and MSSA are designed to identify temporal recurrent patterns in one-dimensional (SSA) and multivariate (MSSA) short noisy time series. Here a brief description of these techniques is presented; Ghil et al. (2002) provide a good overview of both techniques and their relation to dynamical theory. SSA is mathematically similar to conventional empirical orthogonal function (EOF) analysis, except that the eigenanalysis is performed on the lag-covariance matrix, as opposed to the covariance matrix. The eigenvalues of the lag-covariance matrix form the singular spectrum. The eigenvectors, often referred to as timeEOFs (T-EOFs), represent temporal recurrent patterns. The first eigenvector is the temporal recurrent pattern that explains the most lag-covariance. The principal components, known as time-PCs (T-PCs), are defined by the projection of the eigenvectors onto the original time series. Oscillatory behavior is represented by a pair of nearly equal eigenvalues, whose associated T-EOFs (and T-PCs) are in quadrature. MSSA is an extension of SSA to multiple time series, and is mathematically identical to extended-EOF analysis. In the case of MSSA, eigenvalue analysis is performed on the lagged cross covariance matrix (i.e., the cross-covariance matrix of lagged vectors of the different time series).

In contrast to classical spectral analysis, SSA/MSSA allows anharmonic behavior to be represented by two T-EOFs and temporal variations of the amplitude of the oscillatory behavior to be captured. In addition, 
SSA/MSSA can be thought of as a statistical eigenanalysis of a dynamical system, where the oscillatory modes provide a picture of the structure of the attractor (Ghil et al. 2002).

As for any multivariate analysis, care must be taken to ensure all variables are given equal weight. In all cases, except for the SST budget analysis, this is achieved by normalizing each variable by its zonal mean standard deviation. In the case of the MSSA of the Niño-3 SST budget of the ICM, all terms are normalized by their standard deviation. All results presented are renormalized to their correct units.

As mentioned above, to provide an enhanced understanding of sub-ENSO, results obtained from an ICM of the tropical Pacific are also analyzed. The ICM consists of an intermediate complexity ocean model coupled to a statistical atmosphere. The dynamical component of the ocean model (Keenlyside 2001; Keenlyside and Kleeman 2002) is an extension of the McCreary (1981) baroclinic modal model to varying horizontal stratification. The model explicitly represents the first 10 baroclinic modes. Two surface layers of horizontally varying thickness are included to represent higher-order modes (or Ekman currents), and also to provide a partial correction for nonlinearity in the zonal momentum equation. The model realistically simulates the equatorial circulation and its variability (Keenlyside 2001). Similar to Zebiak and Cane (1987), an SST equation is solved in the model's surface layer. However, unlike in Zebiak and Cane (1987), the subsurface entrainment temperature is calculated empirically from model sea surface pressure anomalies using an EOF-based statistical model (Zhang et al. 2005a), similar to that used by Barnett et al. (1993) to estimate wind stress anomalies from SST anomalies. Ten EOFs are retained in the model. This method has been demonstrated to better represent entrainment temperature variability (Zhang et al. 2005a). The statistical atmosphere model (Zhang et al. 2003, 2005b) is based on singular value decomposition (SVD) of the covariance matrix calculated from observed SST and surface wind stress (e.g., Syu and Neelin 2000). The wind stress data are the ensemble mean of 24-member ECHAM4.5 simulations, forced by observed SST anomalies. The first five singular vectors are retained in the model. Additionally, the strength of the atmospheric response to SST is modulated by a constant factor, commonly referred to as the coupling constant. Both atmospheric and entrainment temperature statistical models are seasonally varying. The model has been demonstrated to produce realistic ENSO variability and good hindcast skill (Zhang et al. 2003, 2005b).

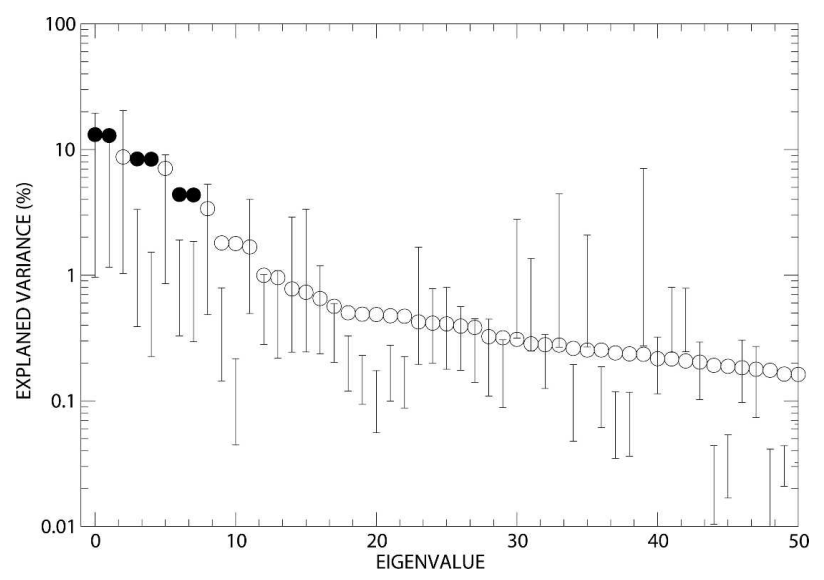

FIG. 2. MSSA spectrum computed for observed equatorial anomalies (w.r.t. the annual mean) of $10-\mathrm{m}$ zonal wind, $20^{\circ} \mathrm{C}$ isotherm depth, SST, and surface zonal currents. The three leading eigenvalue pairs (filled dots) correspond to ENSO, the annual cycle, and sub-ENSO, in decreasing order of explained variance. Error bars indicate the $95 \%$ confidence interval for a red-noise process as calculated with the Monte Carlo method of Allen and Robertson (1996) using 100 realizations of a fitted red-noise process. Data are from the TOGA/TAO array (from $165^{\circ} \mathrm{E}, 170^{\circ} \mathrm{W}$, $140^{\circ} \mathrm{W}$, and $110^{\circ} \mathrm{W}$ ) for the period June $1991-$ September 2002 . A window length of 48 months is used in the MSSA calculation.

\section{Observations}

MSSA of observations of zonal wind (UWND), $20^{\circ}$ isotherm depth, SST, and zonal current (ZC) anomalies (wrt the annual mean) at the equator reveal three pairs of approximately equal variance explaining eigenvalues (Fig. 2). The T-EOFs of each of these pairs are also in quadrature with each other. The first pair represents ENSO, with an explained variance of $25.2 \%$; eigenvalues 4 and 5 capture the annual cycle, with $16.2 \%$ explained variance. The third pair of eigenvalues (7 and 8) represents a mode of variability with an 18-month period, and with $8.5 \%$ explained variance. The annual cycle and sub-ENSO modes are significantly different from a red-noise process, while ENSO is only marginally different. The latter is no doubt due to the relatively short period considered. Significance is tested with the Monte Carlo method of Allen and Robertson (1996). The third eigenvalue with $9 \%$ explained variance captures the trend over the period, which is most obvious in zonal currents (Fig. 1d). The sixth eigenvalue with 7\% explained variance corrects for El Niñolike variations at the start and end of the period, and for nonlinearity/skewness of the 1997/98 El Niño. Variations associated with the third and sixth eigenvalues will not be discussed further. The correspondence between the three MSSA eigenpairs and the observed modes of 
(a) UWND $\left(\mathrm{ms}^{-1}\right)$

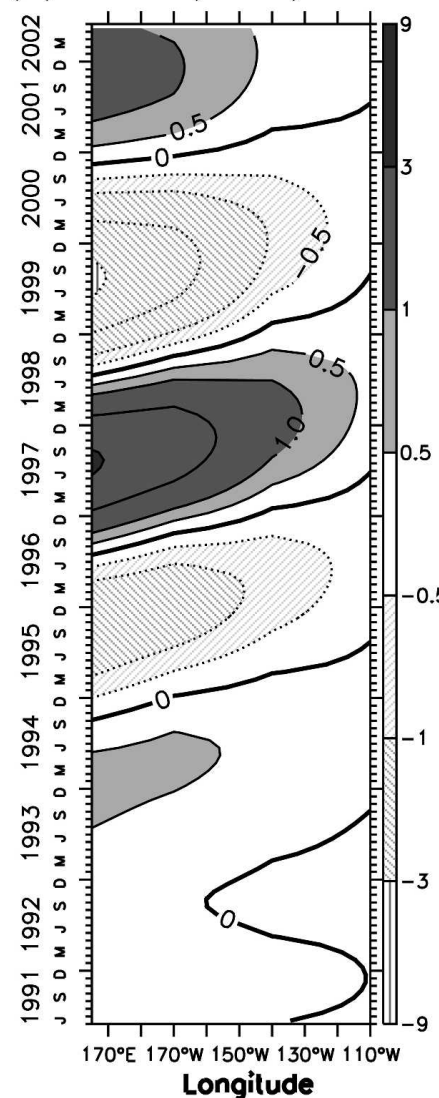

(b) $\mathbf{Z 2 0}(\mathrm{m})$

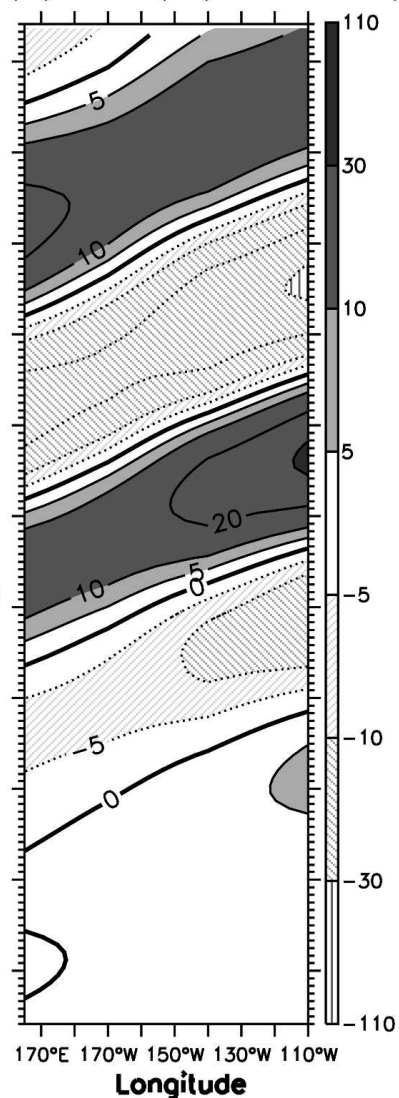

(c) SST $\left({ }^{\circ} \mathrm{C}\right)$

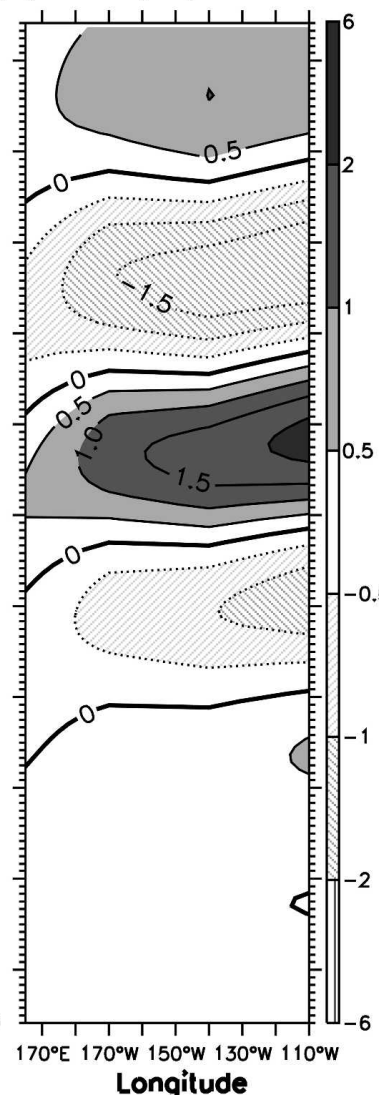

(d) $\mathrm{ZC}\left(\mathrm{cm} \mathrm{s}^{-1}\right)$

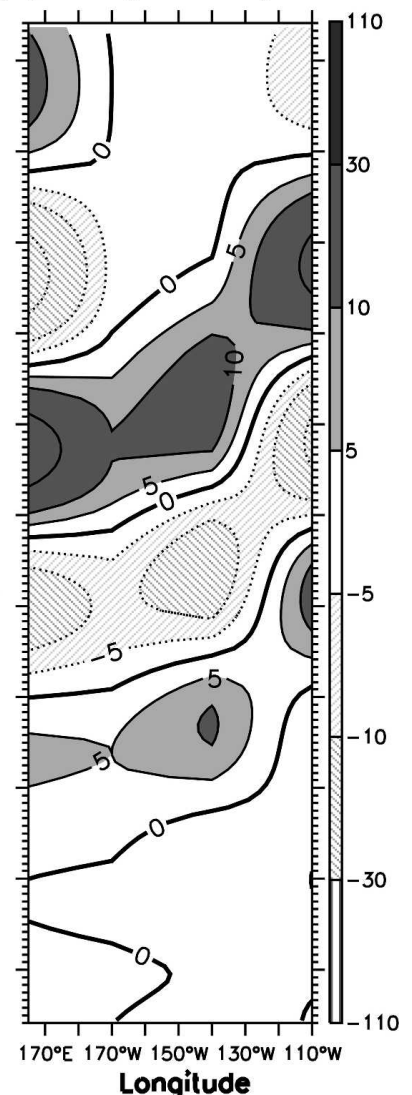

FIG. 3. Observed ENSO mode anomalies along the equator of (a) 10-m zonal wind, (b) $20^{\circ} \mathrm{C}$ isotherm depth, (c) SST, and (d) surface zonal currents for the same period as in Fig. 1, and with the same shading and contours.

variability is now described, with particular attention to sub-ENSO.

\section{a. ENSO}

The MSSA reconstructed ENSO mode captures the equatorial zonal wind, $20^{\circ}$ isotherm depth, SST, and zonal current variations associated with the 1997/98 and 2000/01 El Niño and the La Niña events of 1995/96 and 1999/2000 (Fig. 3). The strength of these variations is between $25 \%$ and $50 \%$ weaker than the corresponding full anomalies (Fig. 1). For example, at the peak of the $1997 / 98$ El Niño MSSA ENSO mode SST exceed $2{ }^{\circ} \mathrm{C}$ in the east, while the observed anomalies exceed $4^{\circ} \mathrm{C}$. Zonal currents variations are approximately $25 \%$ the strength of the observed anomalies. Up to $25 \%$ of these differences are accounted for by sub-ENSO (see below).

Information on the ENSO mode dynamics can be inferred from the Hovmoeller diagrams. They show zonal wind, thermocline depth, and SST to be the important variables (Fig. 3). SST and zonal wind varia- tions are more or less in phase with each other, which is a signature of the positive Bjerknes feedback. In the east, thermocline depth variations lead SST variations by approximately one month, and are apparently the dominant factor controlling them. They themselves are almost in balance with the surface zonal winds [i.e., weaker (stronger) zonal winds with reduced (enhanced) east-west thermocline slope]. It can also be seen that zonal average $20^{\circ}$ isotherm depth variations are roughly in quadrature with eastern Pacific SST variations. In other words, the memory of the system is held in the ocean heat content. The equatorial heat content anomalies are preceded by off-equatorial heat content variations (not shown), both of which appear controlled by long equatorial wave activity. Thus, the dynamics revealed by the MSSA are consistent with both the delayed action (Schopf and Suarez 1988; Battisti and Hirst 1989) and recharge-discharge (Jin 1997a,b) oscillator theories, and the analysis of TAO/ TRITON data by Meinen and McPhaden (2000).

The relative weakness of the zonal current variations 
(a) UWND $\left(\mathrm{ms}^{-1}\right)$

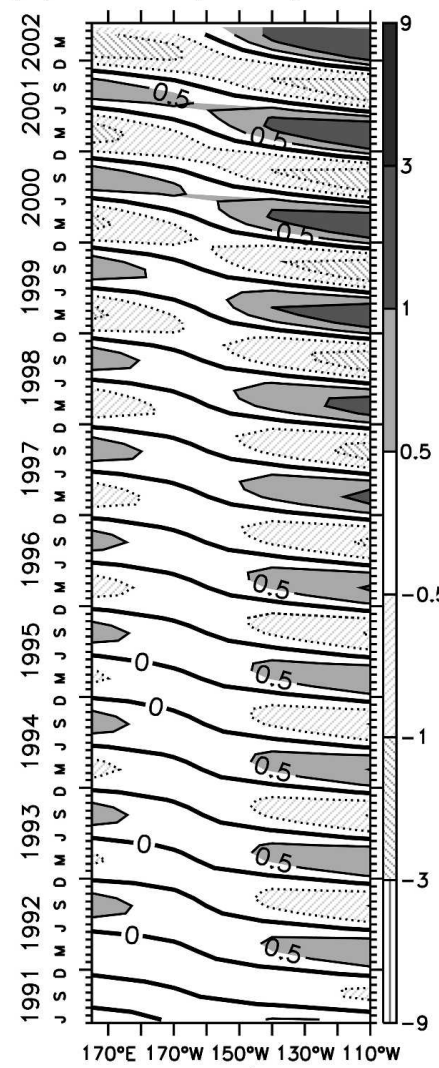

Longitude (b) $\mathbf{Z 2 0}(\mathrm{m})$

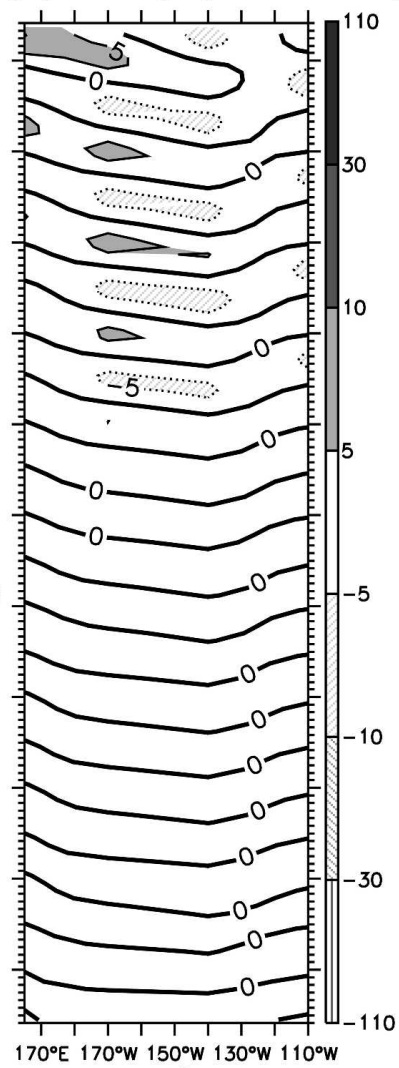

Longitude (c) SST $\left({ }^{\circ} \mathrm{C}\right)$

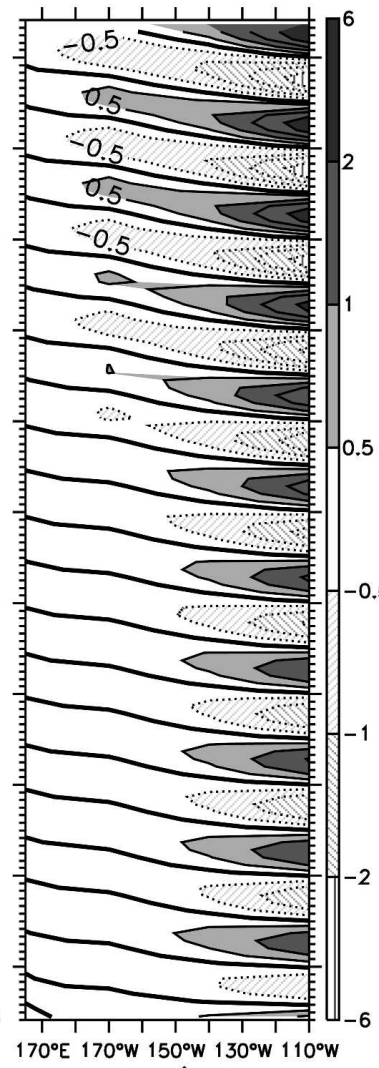

Longilude (d) $\mathrm{ZC}\left(\mathrm{cm} \mathrm{s}^{-1}\right)$

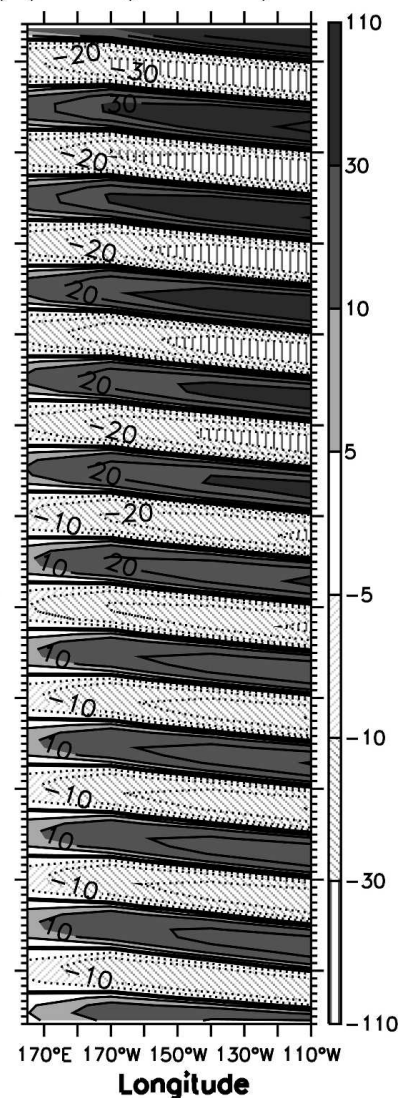

FIG. 4. Observed annual cycle mode anomalies along the equator of (a) $10-\mathrm{m}$ zonal wind, (b) $20^{\circ} \mathrm{C}$ isotherm depth, (c) SST, and (d) surface zonal currents for the same period as in Fig. 1, and with the same shading and contours.

suggests they play a minor role in the ENSO picture. In the west they contribute constructively to the SST variations, and in the east destructively (Figs. 3c,d). This effectively modifies the zonal propagation characteristics of the ENSO mode, which in turn will influence the atmospheric response. Thus, overall the effect of zonal currents may be interpreted as adding an SSTmode characteristic to the thermocline mode, or in other words giving it a hybrid nature. The evolution of the zonal current variations, despite their curious appearance, is relatively easily understood: in the west they seem primarily wind forced, while in the east the pressure gradient dominates.

\section{b. Annual cycle}

The MSSA reconstructed annual cycle corresponds closely with the conventionally calculated one. The annual cycle has largest amplitudes in the eastern Pacific. The surface water in this region warms up from February through April and cools down from August through October (Fig. 4). The warming (cooling) of SST is as- sociated with almost in-phase weakening of the surface zonal wind and current variations. These variations propagate westward together into the central Pacific. The weak thermocline variations exhibit a complex relationship to the other fields that can be understood in terms of long equatorial waves ( $\mathrm{Yu}$ and McPhaden 1999).

In the case of the annual cycle, surface zonal wind and current and SST appear to be the important variables. Zonal wind variations apparently lead the SST and zonal current variations by about a month, but this is nonetheless consistent with a positive atmosphereocean feedback. The zonal wind variations are associated with seasonal changes in the position of the ITCZ, which is itself primarily controlled by surface insulation changes. The zonal current variations are obviously forced directly by the surface wind changes. The currents in turn contribute constructively to the SST variations, and hence appear an important part of the positive feedback loop. Both variations are themselves almost exactly in phase, which implies that the SST 
(a) UWND ( $\left.\mathrm{ms}^{-1}\right)$

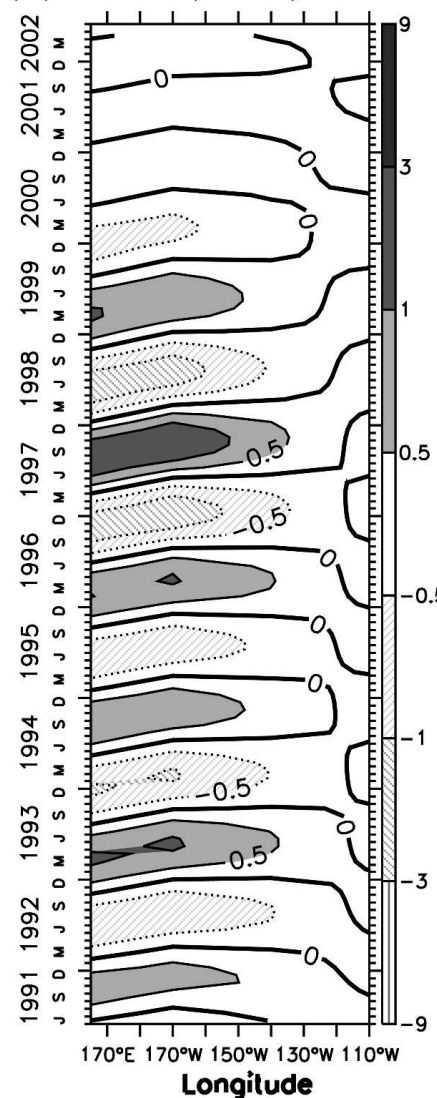

(b) $Z 20(m)$

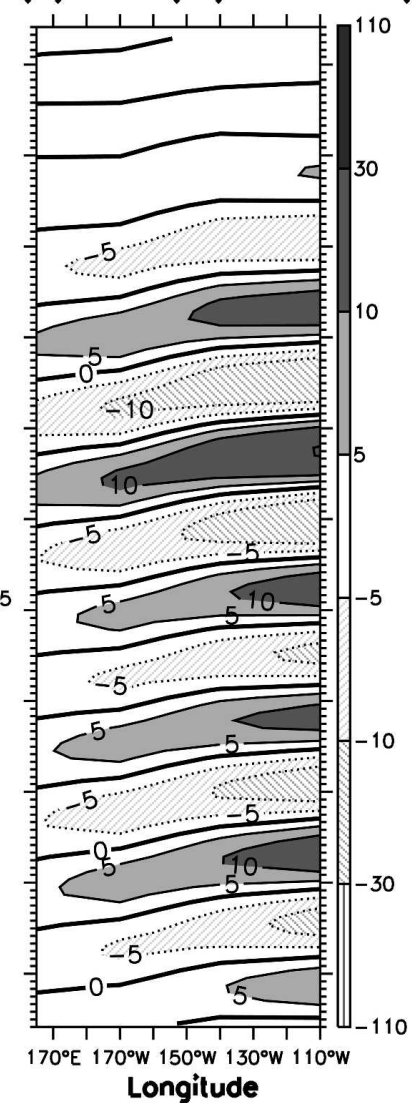

(c) SST $\left({ }^{\circ} \mathrm{C}\right)$

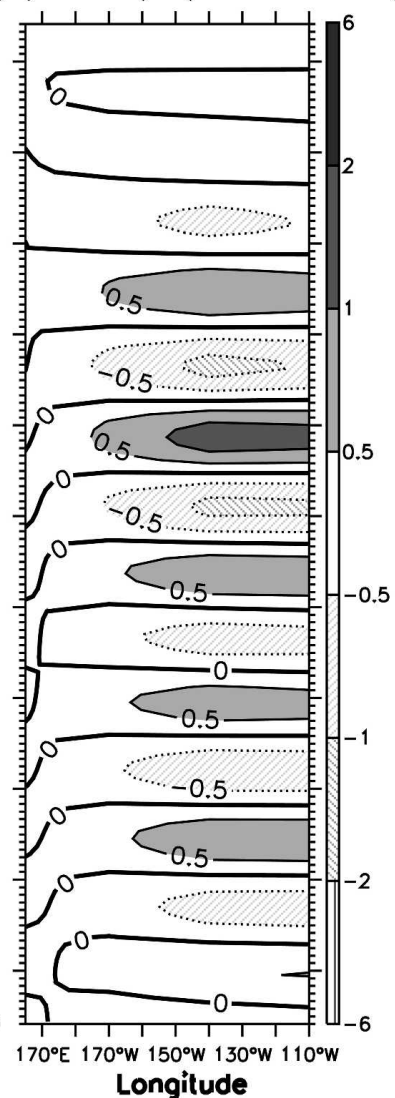

(d) ZC $\left(\mathrm{cm} \mathrm{s}^{-1}\right)$

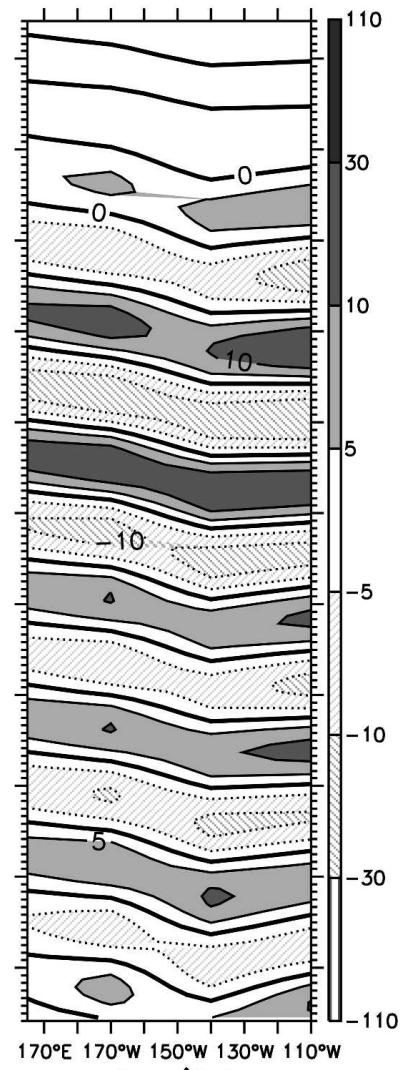

Longilude

FIG. 5. Observed sub-ENSO mode anomalies along the equator of (a) $10-\mathrm{m}$ zonal wind, (b) $20^{\circ} \mathrm{C}$ isotherm depth, (c) SST, and (d) surface zonal currents for the same period as in Fig. 1, and with the same shading and contours.

variations are controlled by the fast wave limit (Jin and Neelin 1993).

As changes in mixed-layer depth (vertical stratification) and upwelling are not included in our analysis, we cannot comment directly on their role in the annual cycle. However, both processes are known to be important (Xie 1995). By inferring changes in both from the zonal wind variations, it can be seen that both processes contribute constructively to the SST variability. Both are specifically important in the fast-wave limit (i.e., in which wave time scales play a minor role). Thus, the features of the annual cycle extracted by the MSSA are consistent with the annual cycle being an SST mode (Jin and Neelin 1993) forced by off-equatorial seasonally driven changes in surface winds ( $\mathrm{Li}$ and Philander 1996).

The MSSA also revealed modulations of the strength of the annual cycle. The annual cycle was apparently weak in the early part of the 1990s, but became significantly stronger after the 1997/98 El Niño event. Such variations contribute to the near-annual variations seen in the full anomalies (Fig. 1), but cannot explain them completely (as discussed below).

\section{c. Sub-ENSO mode}

The third eigenvalue pair is associated with a mode that has a period of 18 months (Fig. 5) and shares many apparent similarities to ENSO: approximately standing SST variations over the central and eastern Pacific (Figs. 5c and 6b); eastward propagating zonal wind variations over the western and central Pacific (Fig. 5b); and eastward propagating $20^{\circ}$ isotherm depth variations that peak in the east, where they precede the SST variations (Fig. 5c) by about a month. However, the zonal current variations (Fig. 5d), which are relatively strong and westward propagating, represent an important difference to ENSO and are indicative of different dynamics.

The relative strength of equatorial SST, zonal wind, zonal current, and thermocline depth variations indicates they all play an important role in the dynamics of this mode (Fig. 5). The zonal wind variations are almost 
in phase with the SST variations, which indicates the Bjerknes positive feedback is active. The SST variations themselves appear largely explained by the thermocline variations, since the ratio between them $\left(0.1^{\circ} \mathrm{C}\right.$ $\mathrm{m}^{-1}$ ) is similar to that for ENSO. Unlike ENSO though, western Pacific heat content variations prior to sub-ENSO extremes are less pronounced, and eastern Pacific average SST and zonal average $20^{\circ}$ isotherm depth variations are not in quadrature with each other. The SST variations lag zonal average $20^{\circ}$ isotherm depth variations by only 3 months, which is shorter than a quarter of the mode's period (4.5 months). On the other hand, zonal average zonal current variations lead the SST variations by 6 months. This is longer than a quarter of the mode's period, and hence the two are also not exactly in quadrature with each other. In the next section, it will be demonstrated, with ICM results, that the SST variations are only explained by the combined effect of both zonal current and thermocline variations. Nonetheless, as zonal current variations lead both thermocline and SST variations, they appear instrumental in bringing about the phase reversal of the mode, playing the role of zonal average heat content for ENSO, and setting the time scale.

The forcing of zonal current and $20^{\circ}$ isotherm depth variations by the zonal winds is easily explained. The zonal gradient in $20^{\circ}$ isotherm depth (i.e., pressure gradient) and the surface zonal winds are in quasi balance, as the zonal gradient in thermocline depth lags the zonal-averaged easterly winds by one month. For ENSO both are in phase with each other. Because of this imbalance, zonal current variations are in disequilibrium with the pressure gradient, with maximum currents associated with minimum zonal pressure gradient and vice versa. In other words, the zonally integrated momentum balance is approximately between the rate of change of the zonally averaged currents $(U)$ and the east-west pressure gradient, that is, $d U / d t=-(\mathrm{He}-$ $\mathrm{Hw}$ ), where $\mathrm{He}$ and $\mathrm{Hw}$ are in this case the east and west Pacific $20^{\circ}$ isotherm depth, respectively. The relationship between currents and the $20^{\circ}$ isotherm depth is consistent with that of a basin mode, that is, uniform near standing current variations out of phase with the zonal pressure gradient.

Sub-ENSO related spatial variations in SST, surface winds, $20^{\circ}$ isotherm depth, and satellite-derived surface currents at transition and peak phases are obtained by regressing an index of sub-ENSO onto the individual fields at 4- and 0-months lag, respectively (Fig. 6). The index used here is the average of reconstructed subENSO SST from an MSSA of SST data from nine TOGA/TAO buoys at the equator between $156^{\circ} \mathrm{E}$ and $95^{\circ} \mathrm{W}$. The analysis is performed for the period August 1994 to May 2004. Please note that while changes corresponding to a $1^{\circ} \mathrm{C}$ peak anomaly are now discussed, since regression values are per degree Celsius, the standard deviation of the sub-ENSO index is only $0.34^{\circ} \mathrm{C}$.

At the transition phase SST are close to zero, while southwesterly winds of up to $2 \mathrm{~m} \mathrm{~s}^{-1}$ are present over the western and central Pacific (Fig. 6a). Strong, nearzonally uniform eastward currents of around $0.5 \mathrm{~m} \mathrm{~s}^{-1}$ are present within $4^{\circ}$ of the equator (Fig. $6 \mathrm{c}$ ). The $20^{\circ}$ isotherm depth variations are also near zonally uniform, with a maximum of $10 \mathrm{~m}$ at the equator and a minimum of $10 \mathrm{~m}$ at $8^{\circ} \mathrm{N}$ (Fig. 6c). No buildup of heat in the west is observed. The structure of the current and $20^{\circ}$ isotherm depth anomalies is highly reminiscent of an equatorial Kelvin wave.

The zonal currents advect water eastward deepening the thermocline there, so that at the peak phase a buildup of water (deepening of the $20^{\circ}$ isotherm by 20 $\mathrm{m}$ ) has occurred in the east, which has caused the zonal currents to weaken significantly there (Fig. 6d). The structure of the zonal currents and $20^{\circ}$ isotherm depth are now highly reminiscent of Kelvin wave reflection into equatorial Rossby waves at an eastern coast. As a consequence of the eastward water movement, the $20^{\circ}$ isotherm has shoaled in the west (Fig. 6b). The eastward advection of warm water and the deepening of the thermocline in the east have caused SST to warm east of $170^{\circ} \mathrm{W}$ within $4^{\circ}$ of the equator, reaching $1.5^{\circ} \mathrm{C}$. (Fig. $6 b)$. Surface winds are also at their maximum, exceeding $2 \mathrm{~m} \mathrm{~s}^{-1}$, converging on the SST in the east (Fig. 6b). Peak SST, surface winds, and $20^{\circ}$ isotherm depth variations resemble those of ENSO, but are more equatorially confined. Zonal current variations are, however, quite different. At the El Niño peak, zonal currents in the east and west are also at their strongest. Over most of the Pacific they are eastward, but in the far east they are westward (Fig. 3d). For sub-ENSO, the currents remain eastward across the equatorial Pacific, but have weakened and are close to zero at the equator in the east (Fig. 6d). This weakening is causing the phase reversal of the sub-ENSO mode.

From the Hovmoeller diagram, the sub-ENSO mode is seen to undergo quite some variability during the analysis period (Fig. 5). From 1992 till the 1997/98 El Niño event it occurs with quite regular amplitude $\left(0.5^{\circ} \mathrm{C}\right.$ in SST) and period (18 months), and SST anomalies are zonally stationary. The sub-ENSO mode reaches its maximum strength during the 1997/98 El Niño event, with SST anomalies of $1^{\circ} \mathrm{C}$, which is about $25 \%$ of the observed full anomaly (Fig. 1). After the 

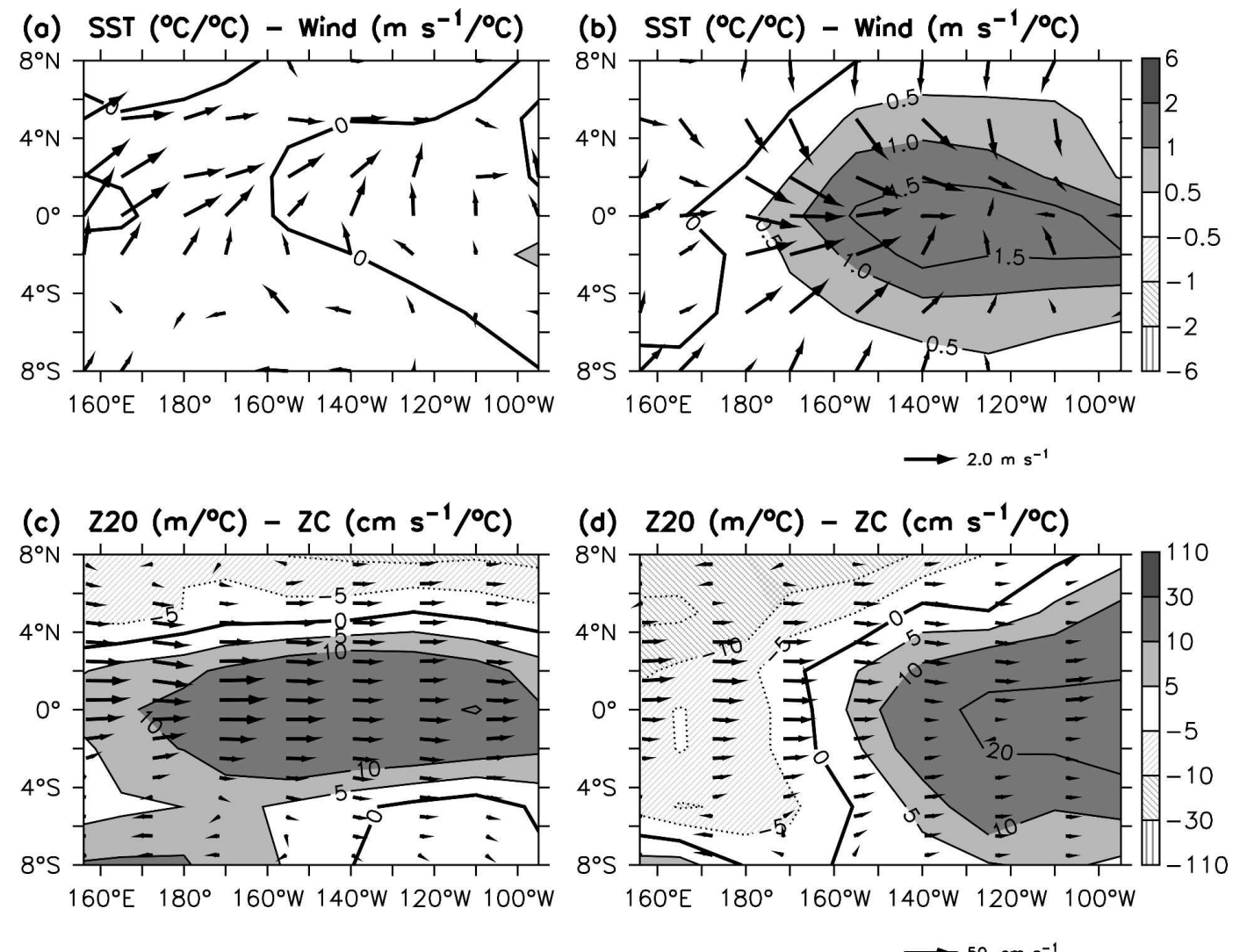

FIG. 6. Regression of SST (shaded) and surface winds (vectors) onto a sub-ENSO SST index at (a) zero-lag and (b) 4-months lag, respectively. (c), (d) Same as in (a), (b) but for $20^{\circ}$ isotherm depth (shaded) and surface currents (vectors). Left (right) panels correspond to the transition (peak) phase. The index used is the averaged sub-ENSO SST from an MSSA of SST data from nine TOGA/TAO buoys at the equator between $156^{\circ} \mathrm{E}$ and $95^{\circ} \mathrm{W}$. The analysis is performed for the period August 1994 to May 2004. Shading and contours as in Fig. 1.

1997/98 El Niño event the sub-ENSO mode weakens. There are also hints that its period shortens and SST variations become westward propagating. The latter are consistent with features seen in the full anomalies (Fig. 1).

By construction, MSSA cannot properly capture changes in frequency. To further investigate such potential changes, MSSA has been repeated separately on two periods: January 1990 to December 1996 and July 1998 to March 2004. Because of a lack of availability of ADCP data prior to 1992, we are restricted to use only SST, zonal wind, and $20^{\circ}$ isotherm depth measurements. No longer restricted to use the four current mooring buoys, data from nine buoys between $156^{\circ} \mathrm{E}$ and $95^{\circ} \mathrm{W}$ are analyzed. In addition, we analyze climatological anomalies (with respect to the analyzed period), since we are interested in frequencies close to annual, but of the variability not associated with the annual cycle.

The two individual MSSA show that the sub-ENSO mode undergoes a strong change in period and amplitude (Fig. 7). The analysis of the period prior to the $1997 / 98$ El Niño event is largely consistent with that above (i.e., the mode has an 18-month period and SST are zonally stationary; Fig. 7a). After the 1997/98 El Niño, the sub-ENSO mode weakens significantly, its period shortens to about 14 months, and SST anomalies are westward propagating. Zonal winds are no longer eastward propagating, and hints of westward propagation are visible over the central and eastern Pacific. During this period, the annual cycle also appears to strengthen (Fig. 4), which together with the sub-ENSO changes largely explain the observed near-annual anomalies post the 1997/98 El Niño (Fig. 1). The changes in the sub-ENSO mode have been attributed to the strong differences in the background state of the two periods (Jin et al. 2003; Kang et al. 2004), and are consistent with our modeling results (described below). These background state changes may also influence the annual cycle. 
(a) UWND $\left(\mathrm{m} \mathrm{s}^{-1}\right)$

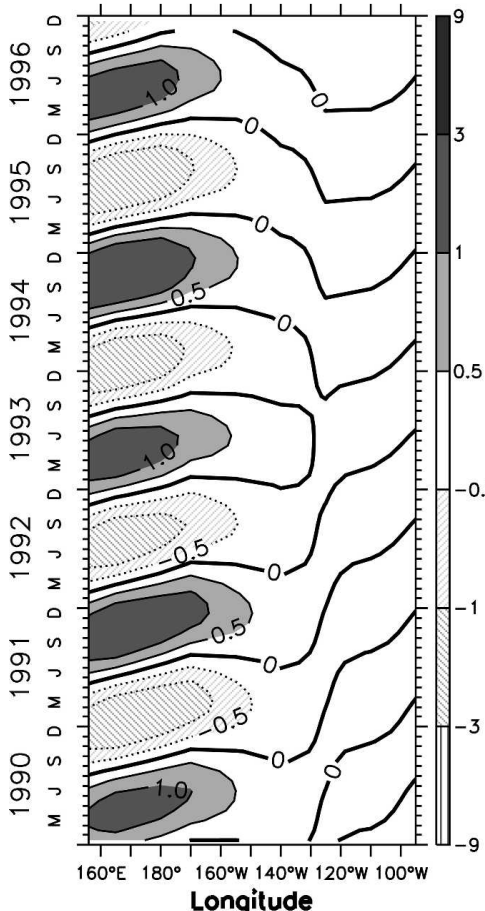

(d) UWND $\left(\mathrm{m} \mathrm{s}^{-1}\right)$

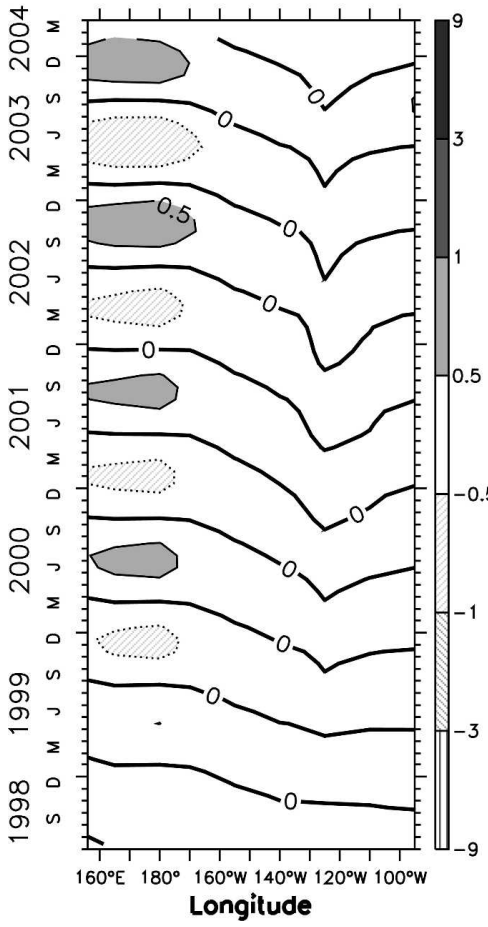

(b) $Z 20(\mathrm{~m})$

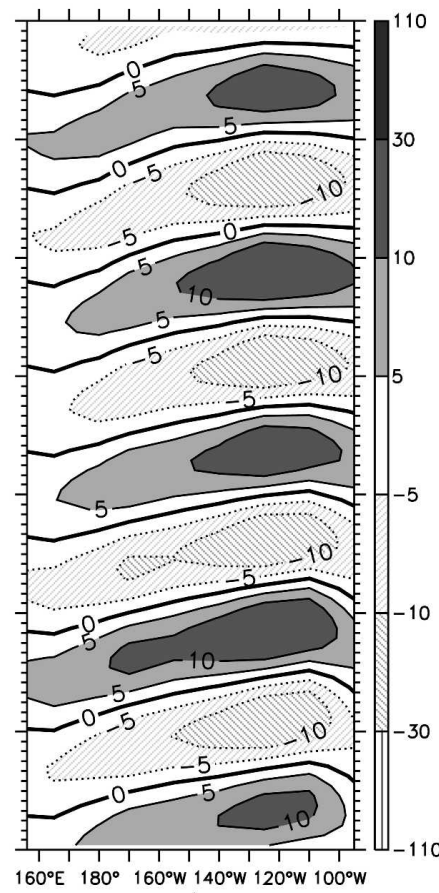

Longitude (e) $Z 20(\mathrm{~m})$

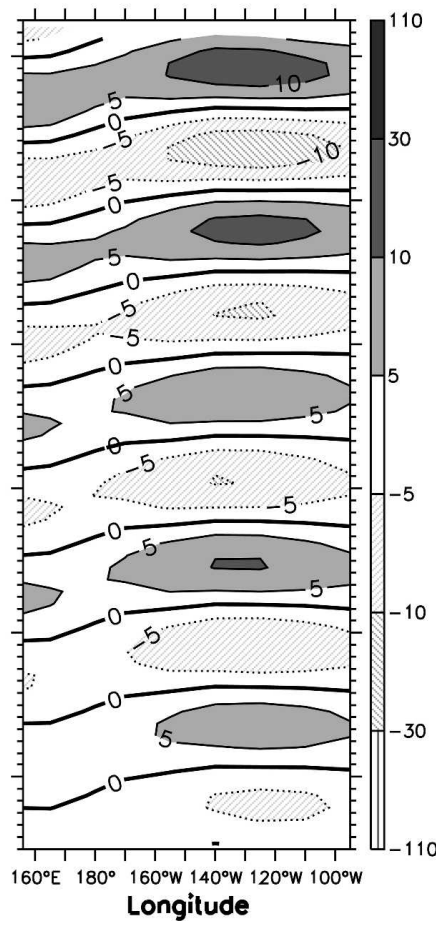

(c) SST $\left({ }^{\circ} \mathrm{C}\right)$

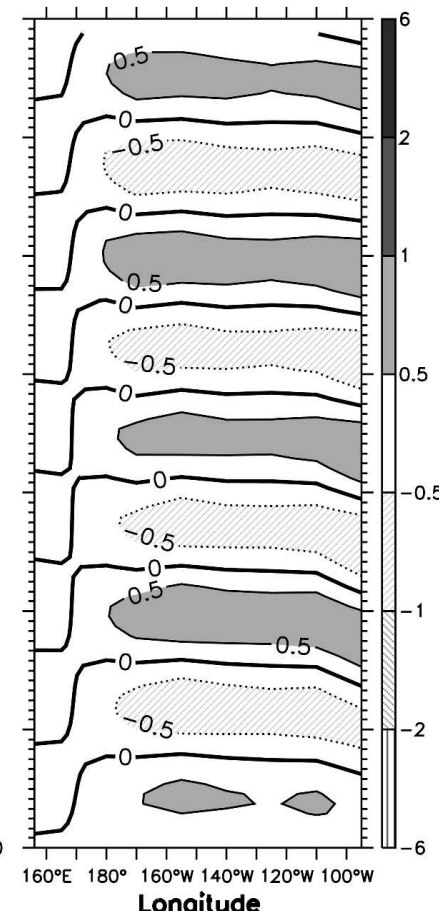

(f) SST $\left({ }^{\circ} \mathrm{C}\right)$

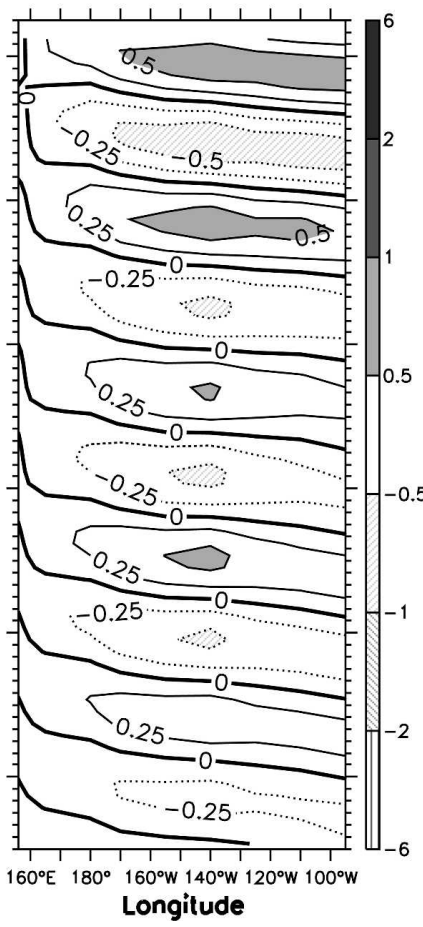

FIG. 7. Equatorial anomalies of (a) zonal wind, (b) $20^{\circ} \mathrm{C}$ isotherm depth, and (c) SST associated with the sub-ENSO mode for the period 1990-96. The mode is obtained from MSSA of TOGA/TAO data from nine locations between $156^{\circ} \mathrm{E}$ and $95^{\circ} \mathrm{W}$. The annual cycle was removed prior to the MSSA, and a window length of 48 months was used. (d)-(f) The anomalies associated with the sub-ENSO mode for the period 1998-2004 [computed analogous to (a)-(c)]. Shading and contours are as in Fig. 1, but with extra contours for $\pm 0.25^{\circ} \mathrm{C}$ added to (f). 
(a) UWND $\left(10^{-2} \mathrm{Po}\right)$

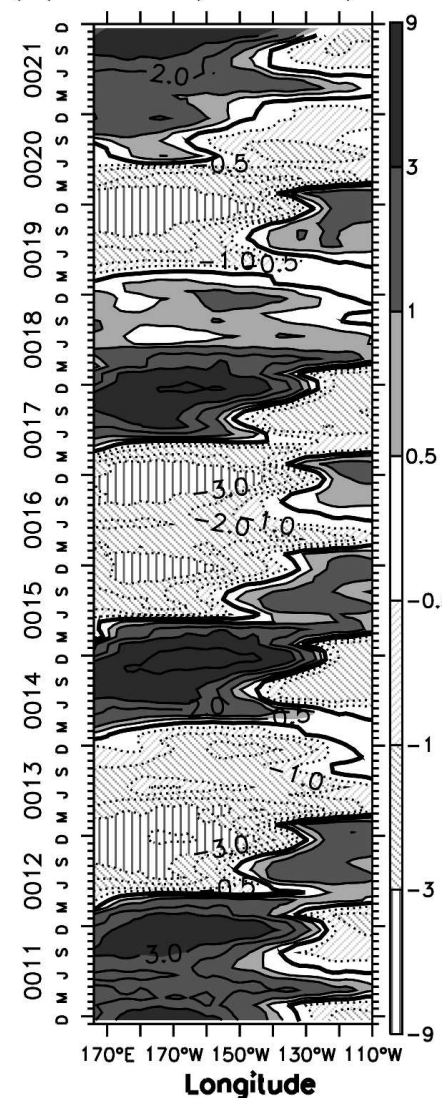

(b) $\mathbf{Z 2 0}(\mathrm{m})$

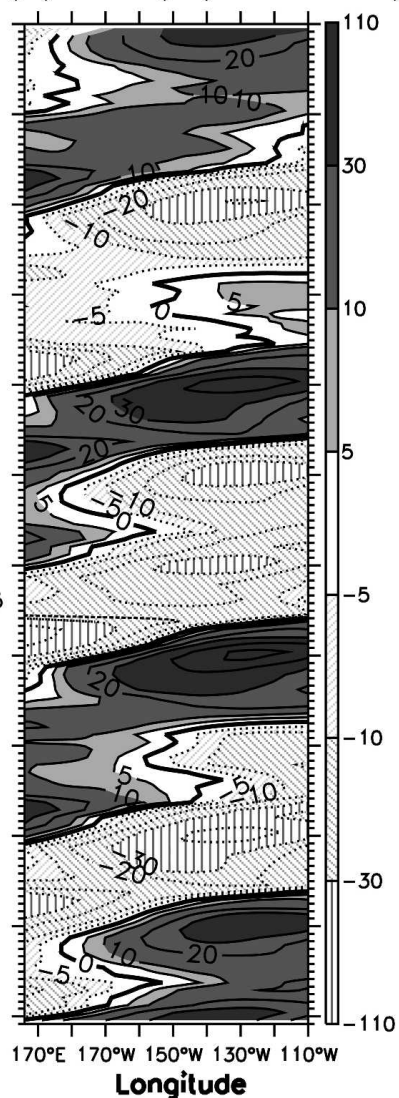

(c) SST $\left({ }^{\circ} \mathrm{C}\right)$

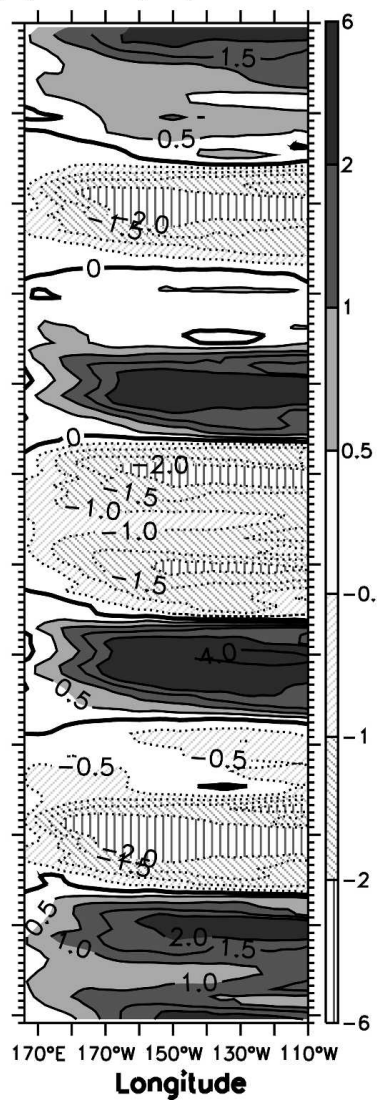

(d) $\mathrm{ZC}\left(\mathrm{cm} \mathrm{s}^{-1}\right)$

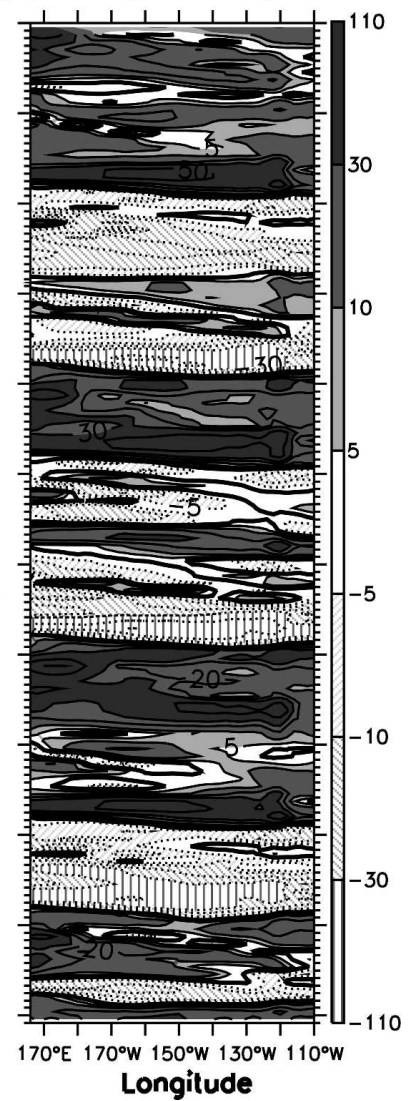

FIG. 8. Anomalies along the equator of (a) surface zonal wind stress, (b) $20^{\circ} \mathrm{C}$ isotherm depth, (c) SST, and (d) surface zonal currents simulated by the ICM for an arbitrary 11-yr period. Shading and contours as in Fig. 1.

\section{ICM analysis}

The analysis of observations described above revealed the existence of three modes of coupled oceanatmosphere variability in the tropical Pacific. Two of these, the annual cycle and ENSO, are relatively well understood. The third mode, sub-ENSO, is not. In this section, results from an ICM (section 2) are presented in support of this mode's existence. To facilitate comparison with observations, the model data are analyzed in an identical manner.

The strength, temporal evolution, and spatial structure of the ICM-simulated interannual variability along the equator (Fig. 8) compares well to observations (Fig. 1). Because of both the model's simplicity and lack of stochastic forcing, the variability is too regular. Two periods can be seen in the Hovmoeller diagrams (Fig. 8): a 3-4-yr ENSO mode, and a near-annual component. As in observations, the latter is most obvious in the zonal current anomalies. There are also some hints of a decadal signal, which is actually the result of the superposition of these two periods, which do not divide each other integrally.
Consistent with the visual inspection, MSSA of the simulated variability identifies two modes of variability (Fig. 9): ENSO, with a 40 -month period and $63 \%$ explained variance, and sub-ENSO, with a 17 -month period and $20 \%$ explained variance. Being an anomaly model, no annual cycle is simulated. Accounting for the annual cycle, the explained variances are about twice those of the observed modes. This is consistent with the exclusion of stochastic variability from the model and the self-sustaining regime the model is in. These also explain why the eigenvalue pairs in the model are more clearly separated from each other and the background (Fig. 9) than those of observations (Fig. 2).

The MSSA reconstructed equatorial zonal wind, $20^{\circ}$ isotherm depth, and SST variations of the simulated ENSO mode (Fig. 10) resemble those of the observed one (Fig. 3). In particular, SST variations are largest in the central and eastern Pacific and are almost zonally stationary. They are preceded by eastward propagating large heat content variations, and are in phase with weakly eastward propagating zonal winds over the western and central Pacific. A major difference to ob- 


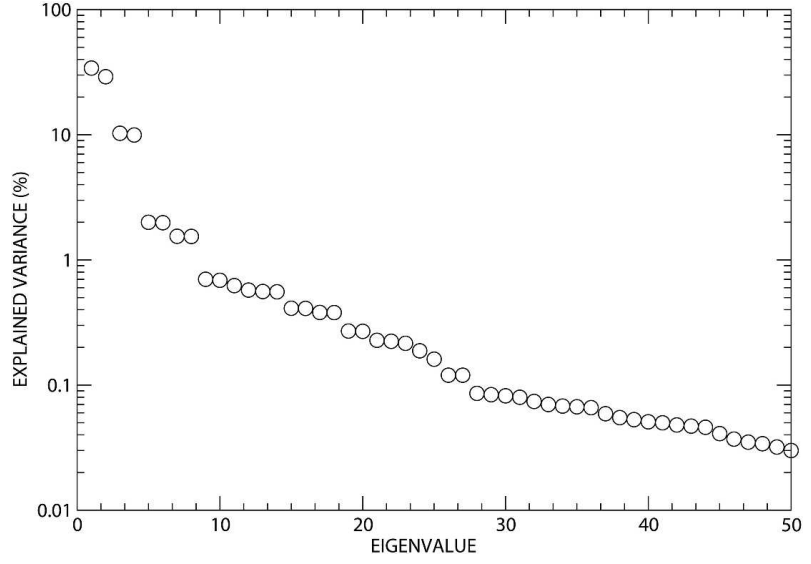

FIG. 9. MSSA spectrum for the ICM, computed from $100 \mathrm{yr}$ of equatorial anomalies of surface zonal wind stress, $20^{\circ} \mathrm{C}$ isotherm depth, SST, and surface zonal currents. Data are sampled at the four TAO locations, and an identical window length of 48 months is used in the MSSA calculation.

servations is found in the zonal currents. In the model, they lead the SST variations and are westward propagating (Figs. 10c,d), whereas in observations they are eastward propagating and lag the SST (Figs. 3c,d).

The differences between simulated and observed zonal currents may arise from both observational and model errors. One prominent problem in the observations is seen in 1996 (Fig. 1d). The averaging of surface current data over the upper $50 \mathrm{~m}$ may also introduce systematic errors (as discussed in section 2). Model errors may arise from the oversimplification of the ocean physics. To assess some of these errors, the MSSA was repeated using data from the Simple Ocean Data Assimilation (SODA) reanalysis (Carton and Giese 2007, manuscript submitted to Mon. Wea. Rev.) averaged over the upper $25 \mathrm{~m}$, the upper $50 \mathrm{~m}$, and from 25 to 50 $\mathrm{m}$ (results not shown). The different vertical averaging was found to have little influence on the results. The zonal current behavior of the ICM and SODA data were in good agreement, which suggests that model simplifications may also not be the main source of error. Despite this agreement, the observed picture is physically very plausible (section 3 ) and it is our opinion that the ICM (and SODA data) underestimates the direct mixed-layer response to surface winds over western and central Pacific. As the lower-order baroclinic response is known to be more important for ENSO, as will also be shown for sub-ENSO, this potential model deficiency should not influence our results significantly.

The strength and phase of simulated sub-ENSO surface zonal winds and currents, $20^{\circ}$ isotherm depth, and SST variations (Fig. 11) are almost identical to those of the observed mode (Fig. 5). In particular, eastern Pa- cific SST and $20^{\circ}$ isotherm depth variations are in phase with surface zonal wind variations to the west. The SST variations are preceded by eastward propagating heat content variations, but with little prior buildup in the west. SST and zonal currents are in clear quadrature with each other.

The good correspondence between the observed and simulated, ENSO and sub-ENSO modes gives us confidence that the ICM captures the essential dynamics of both modes, and thus is useful to study them. First, the SST budget of both modes is analyzed to see if they are consistent with the inferences made above. The heat budget of each mode is obtained by MSSA of the Niño-3 averaged SST and SST tendencies. In the case of ENSO, Niño-3 SST is controlled by vertical advection and mixing (i.e., subsurface related changes), surface thermal damping, and meridional advection (Fig. 12a). Zonal advection only makes a weak contribution. The vertical advection and mixing term is clearly the driving term. As vertical advection is confined to the equator, this term is dominated by vertical mixing, which is proportional to subsurface temperature anomalies. Thus, the ICM ENSO mode is a thermocline-driven mode, consistent with present understanding, and the interpretation of the observed MSSA mode (section 3).

In the case of the sub-ENSO mode, Niño-3 SST is controlled by vertical advection and mixing, surface thermal damping, and zonal and meridional advection (Fig. 12b). The driving terms are now vertical advection and mixing, and zonal advection. The zonal-advective term, however, leads the vertical tendency, and thus despite being weaker than the vertical term, controls the time scale of the sub-ENSO mode. The vertical term can be thought of as a delayed amplification of the initial zonal-advection signal. The zonal-advective term is controlled equally by the mean advection of SST anomalies and the anomalous advection of the mean SST, which act as damping and forcing terms, respectively. Thus, the ICM sub-ENSO mode is driven by the zonal-advective feedback, which is consistent with the inference made from observations (section 3 ).

Although the dynamical analysis provides a physically consistent picture of the sub-ENSO mode, our analyses so far have been statistical, and so a possibility exists that we are investigating a statistical artifact. To verify that the sub-ENSO mode is a dynamical mode, a set of sensitivity experiments have been performed, which we refer to as resonant forcing experiments. The experiments are as follows: The coupling constant in the model is set to a level (0.95), such that the system is in a weakly damped regime and no self-sustaining variability exists. A weak harmonic forcing is then added to 
(a) UWND $\left(10^{-2} \mathrm{Po}\right)$

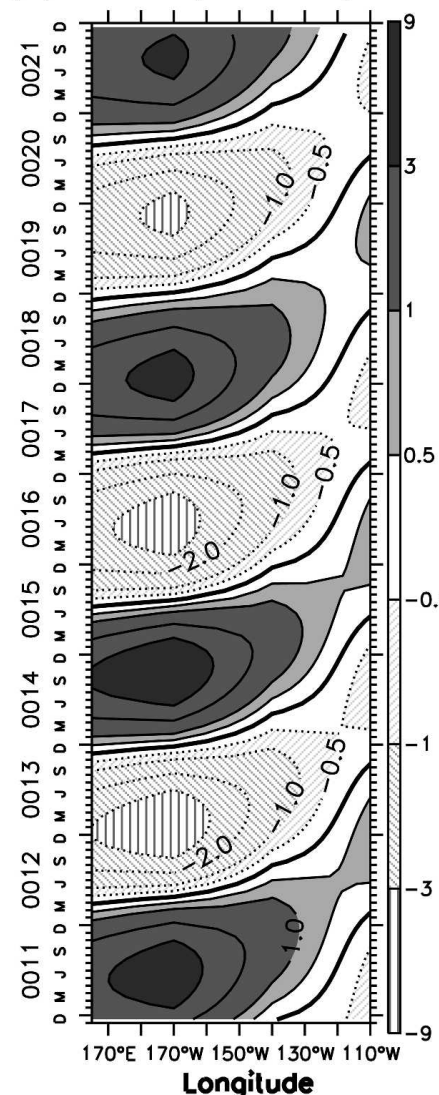

(b) $\mathbf{Z 2 0}(\mathrm{m})$

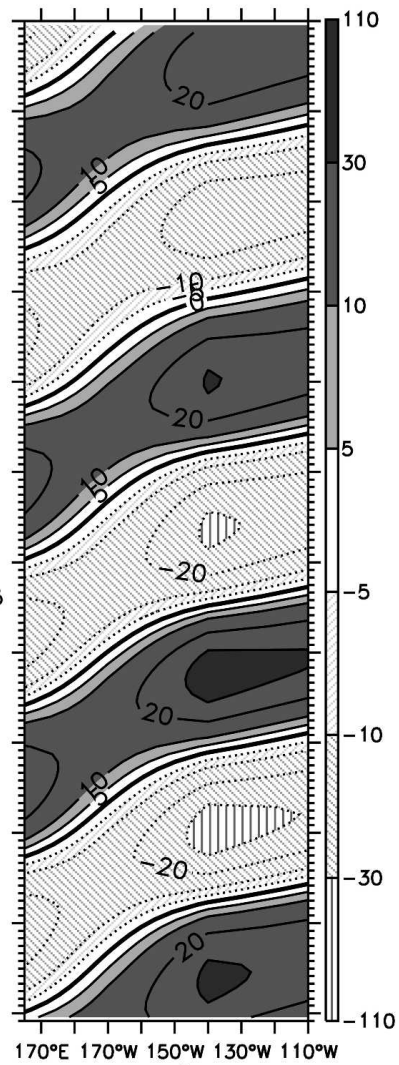

Longitude (c) SST $\left({ }^{\circ} \mathrm{C}\right)$

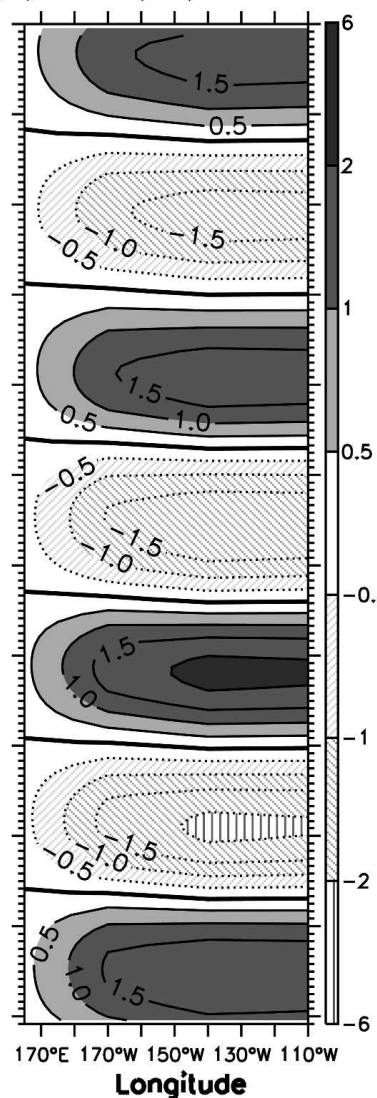

(d) $\mathrm{ZC}\left(\mathrm{cm} \mathrm{s}^{-1}\right)$

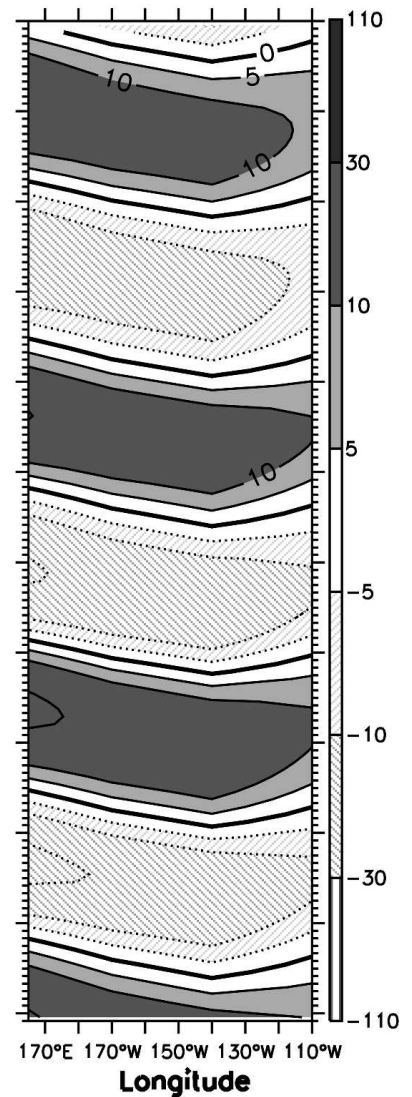

FIG. 10. ENSO mode anomalies along the equator of (a) surface zonal wind stress, (b) $20^{\circ} \mathrm{C}$ isotherm depth, (c) SST, and (d) surface zonal currents simulated by the ICM for the 11-yr period in Fig. 8. Shading and contours as in Fig. 1.

the zonal winds with the spatial pattern of the first zonal wind EOF. The strength of the forcing is less than $4 \%$ of the variability in the control simulation. The forcing frequency is then varied in different experiments, to investigate the response of the coupled system to forcing frequency. The idea behind this experimental design is that when the forcing frequency matches that of a natural mode of the system (assuming the spatial pattern projects onto the mode) a resonance will be induced.

The response of the coupled system in terms of the standard deviation of Niño-3 SST suggests that three modes may exist in the system: ENSO, sub-ENSO, and a biennial mode (Fig. 13a). The frequency response of the system reveals a more complex picture (Fig. 13b). Two clear spectral bands exist at all forcing frequencies between 12 and 80 months. This behavior can only result from nonlinearity. The increased power along the main diagonal of the figure shows the linear response of the system. Along this diagonal enhanced power is seen about the model's ENSO period of 40 months, but also at several multiples of a year ( 24,36 , and 48 months). A peak at the sub-ENSO period of 17 months is not obvious in the linear response. The second band of power, which falls along a curve that is approximately inversely related to the forcing frequency, represents the nonlinear response of the system. Enhanced power is found on this curve at 17, 24, and 40 months. The picture is consistent with two damped oscillators that are coupled nonlinearly. The least damped oscillator (ENSO in our case) dominates the frequency response at all forcing frequencies. In this picture, the biennial component results from the intersection of the linear and nonlinear responses. The nonlinear interaction between subENSO and ENSO is a new result, which may have implications for predictability. Identifying the mechanisms behind this interaction is left for future investigation.

The relative strength and characteristics of both ENSO and sub-ENSO should also depend on the background state, since it modulates the strength of the anomalous SST tendency terms, which control these 
(a) UWND $\left(10^{-2} \mathrm{~Pa}\right)$

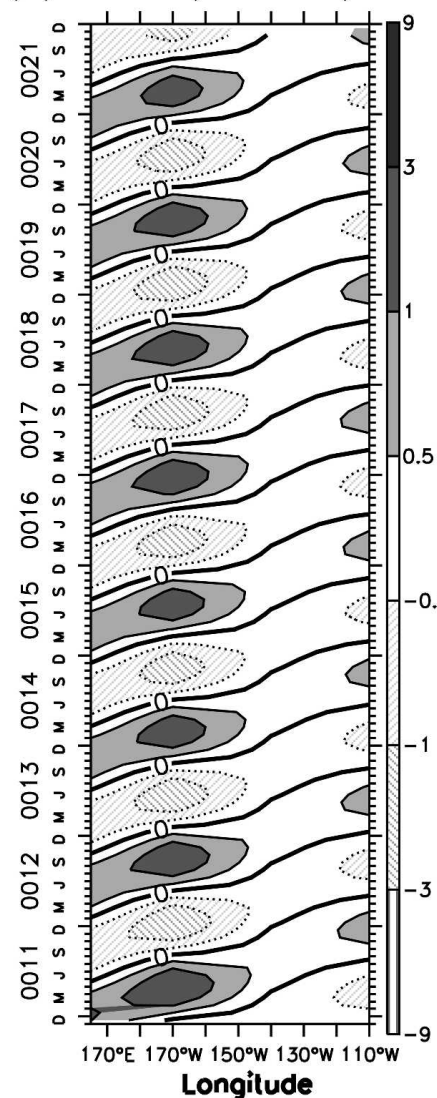

(b) $Z 20(m)$

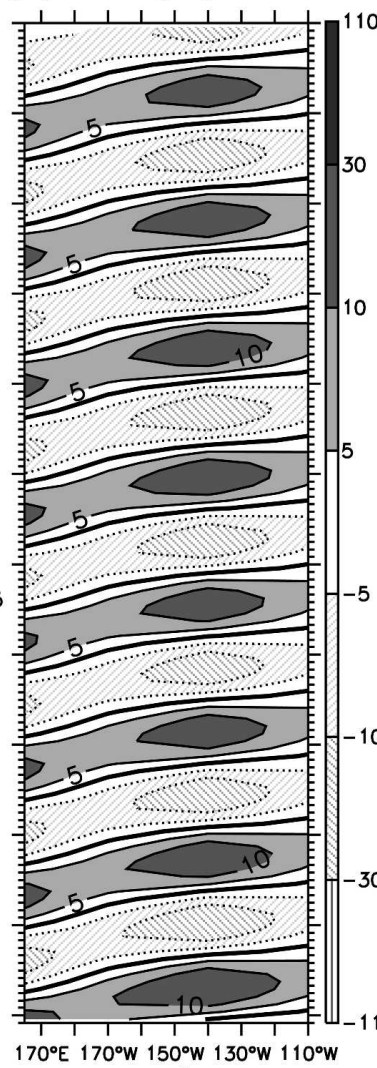

Longitude (c) SST $\left({ }^{\circ} \mathrm{C}\right)$

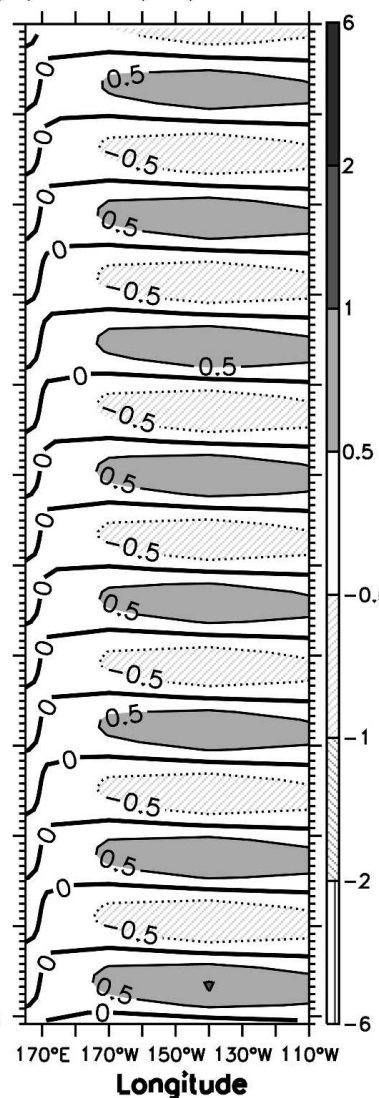

(d) ZC $\left(\mathrm{cm} \mathrm{s}^{-1}\right)$

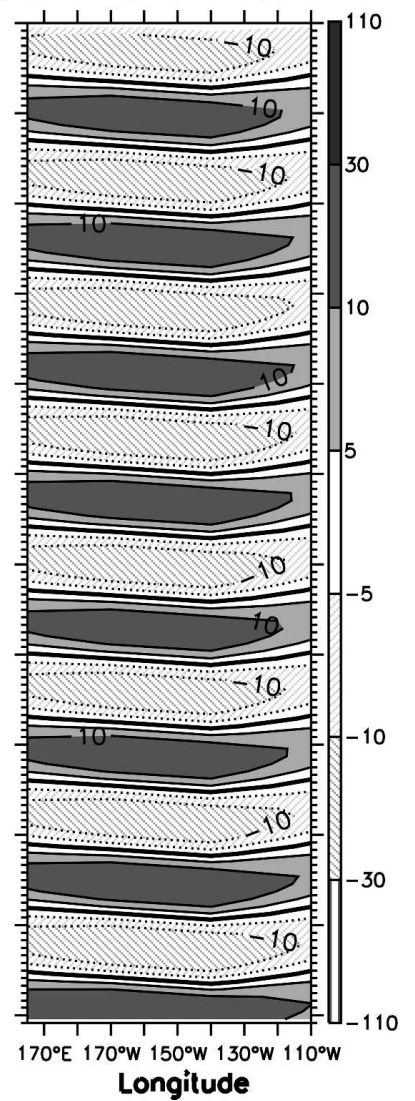

FIG. 11. Sub-ENSO mode anomalies along the equator of (a) surface zonal wind stress, (b) $20^{\circ} \mathrm{C}$ isotherm depth, (c) SST, and (d) surface zonal currents simulated by the ICM for the 11-yr period in Fig. 8. Shading and contours as in Fig. 1.

characteristics. Such a mechanism has already been proposed for both ENSO (e.g., An and Jin 2001; Federov and Philander 2001) and sub-ENSO (Jin et al. 2003; Kang et al. 2004). Our observational analysis shows that the sub-ENSO mode's characteristics change in a manner consistent with these ideas [i.e., if the background SST gradient is enhanced (relaxed) as it was after (before) 1997/98, the zonal-advective feedback will be strengthened (weakened), leading to a shorter (longer) characteristic period]. To investigate if such changes in the relative importance of zonal and vertical terms in the SST equation may affect the characteristics of the sub-ENSO mode, a series of experiments were performed in which the relative importance of these terms was varied explicitly. This was achieved by weighting the zonal-advective tendency by $2 \beta$, and the vertical mixing and advection tendencies by $2(1-\beta)$, where $\beta$ was a constant that varied between 0 and 1 . Thus, for $\beta=0.5$ no changes to the model are made, and for $\beta<0.5$ the importance of zonal term relative to the vertical tendencies is reduced, and vice
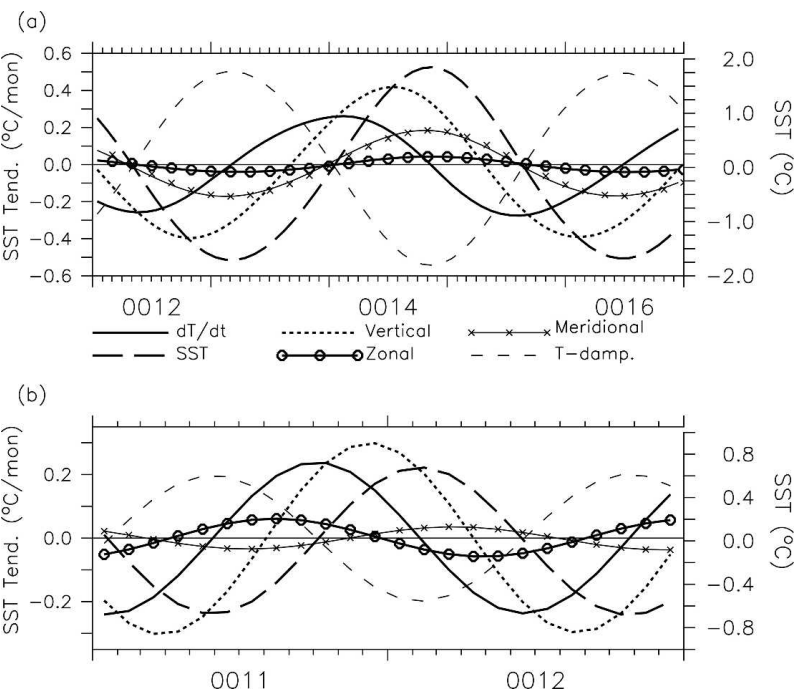

FIG. 12. Heat budget of Niño-3 averaged SST anomalies for (a) ENSO and (b) sub-ENSO modes of variability calculated from ICM control simulation. ENSO (sub-ENSO) anomalies are for an arbitrary 5- (2-) yr period. Time (yr) is shown on the $x$ axis. 
(a)

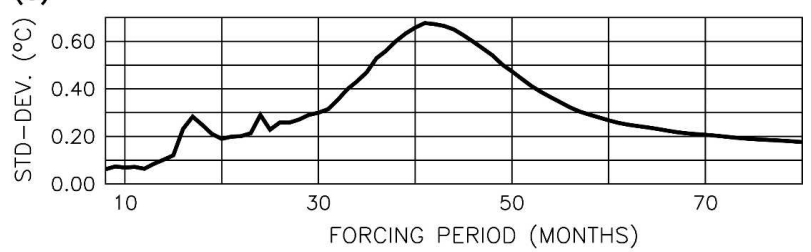

(b)

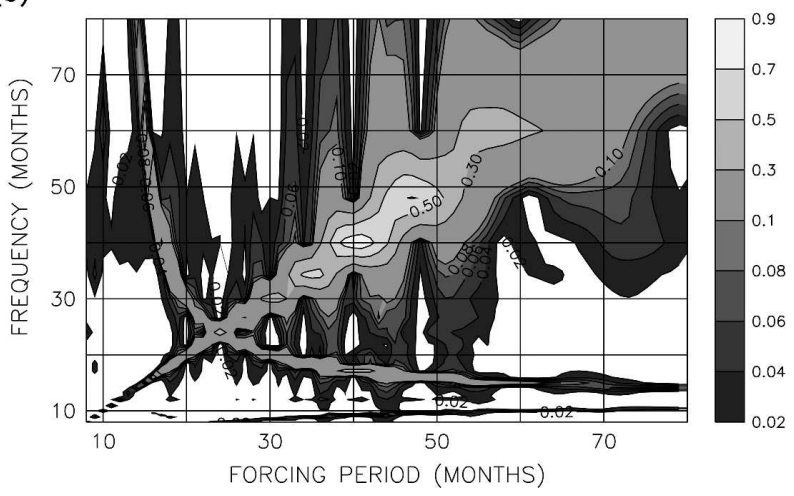

FIG. 13. The coupled response of the ICM to periodic wind forcing as expressed in the (a) standard deviation and (b) power spectral density of Niño SST anomalies as a function of the forcing period. Analyses were performed on the last $20 \mathrm{yr}$ of 30-yr ICM simulations, in which the atmospheric coupling constant was 0.95 , corresponding to a weakly damped regime.

versa for $\beta>0.5$. Within the range of $\beta$ values for which oscillatory behavior was maintained, the observed changes in period and propagation characteristics of the sub-ENSO mode could be quite well reproduced by the model. In particular, when the importance of zonal advective tendency was decreased by $40 \%$ and vertical tendency increased by $40 \%$ (i.e., $\beta=0.3$ ), the sub-ENSO period shifted to 18 months and SST anomalies were weakly eastward propagating (Fig. 14a). In the converse experiment, the sub-ENSO period decreased to 14 months and SST anomalies propagated westward (Fig. 14c).

\section{Discussion and conclusions}

Recent observations have highlighted the existence of tropical Pacific climate variability with a $1-2$-yr period (Fig. 1). This variability is present throughout the 130-yr instrumental record (Jin et al. 2003). Although the variability has some similarity to ENSO, its time scale and clear differences in the relationship among equatorial atmospheric and oceanic fields suggest it arises from a different mechanism. The principal aim of this work was to understand the causes of this variability, and in particular to 1) determine whether it represents an independent mode of climate variability, and if so, 2) identify its physics and 3) the factors controlling its activity.

For this purpose, we analyzed in situ observations from the TAO/TRITON array (McPhaden et al. 1998), satellite-derived currents from the OSCAR dataset (Bonjean and Lagerloef 2002), and simulations with an ICM (Zhang et al. 2003). The TAO/TRITON data analyzed here include zonal wind, $20^{\circ}$ isotherm depth, and SST from 1990 until 2004, and 0-50-m average zonal currents from 1991 until 2002. The primary analysis tool was MSSA, a statistical technique designed to identify oscillatory modes of variability in short noisy time series (Ghil et al. 2002).

MSSA of observations identifies three oscillatory modes of variability: ENSO, annual cycle, and subENSO, explaining $25.2 \%, 16.2 \%$, and $8.5 \%$ of the variance, respectively. The MSSA ENSO and annual cycle modes correspond closely with their accepted pictures. Sub-ENSO has a period of between 14 and 18 months, and surface zonal winds, $20^{\circ}$ isotherm depth, and SST variations that are similar to those of ENSO. The two modes are however clearly distinguished by the zonal current variations. ENSO-related zonal currents occur in phase with SST variations, and appear to be of secondary importance. Sub-ENSO-related zonal currents are in near quadrature with SST variations and determine the time scale. Thus, they are of primary importance. Thermocline variations act only as an amplifier of the zonal-current-induced SST signal. Analysis of the SST budget of the ICM, which simulates both ENSO and sub-ENSO variability realistically, further shows that the mode arises from the zonal-advective feedback (i.e., anomalous advection of mean SST). It is additionally shown that while both ENSO and sub-ENSO coexist in the model they are coupled nonlinearly.

The picture revealed by our work is in many ways consistent with that of Jin et al. (2003) and Kang et al. (2004). These authors argue this variability is due to the Pacific basin mode, destabilized by the zonal-advective feedback. This is based on the structure and relationship between zonal current and thermocline depth variations (i.e., maximum zonal current variations in the center of the basin, which are out of phase with east-west thermocline depth variations). However, the Pacific basin mode's theoretical period of 8 months is approximately half that of the sub-ENSO mode. On this basis, it seems unlikely that the sub-ENSO mode is simply a resonantly excited basin mode. However, Jin and Neelin (1993) have shown that air-sea coupling can effectively double the period of basin mode.

The sub-ENSO mode's characteristics are seen to change during the analysis period. Prior to the 1997/98 El Niño event, it has a period of 18 months and standing 
(a)

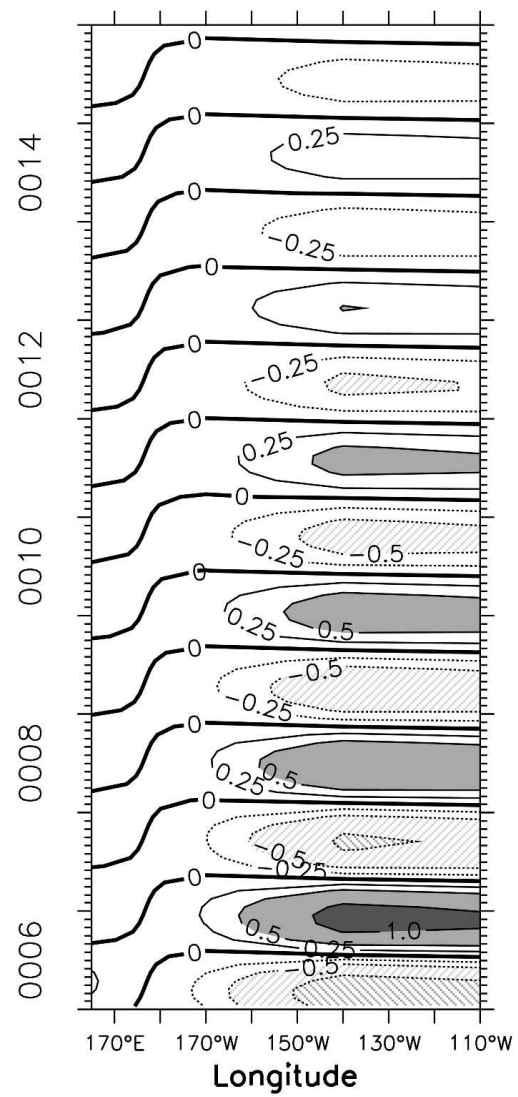

(b)

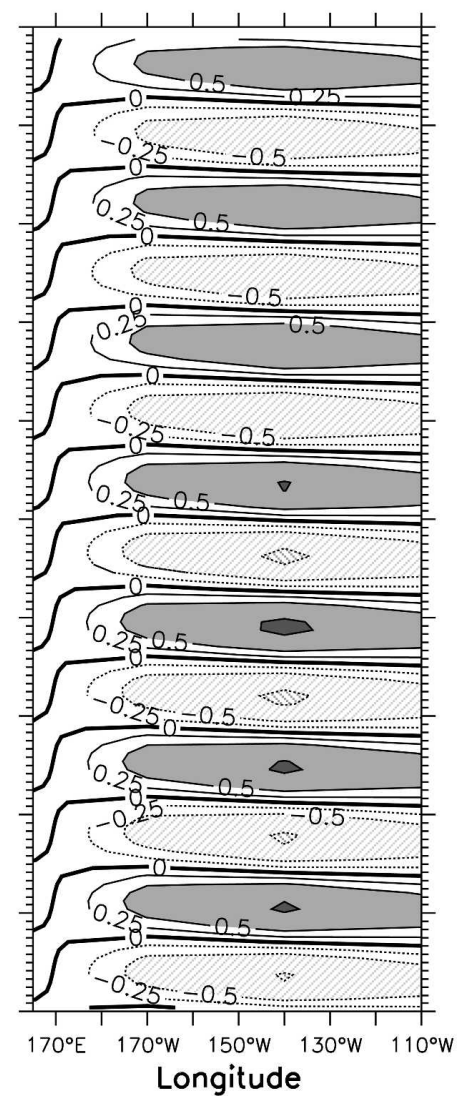

(c)

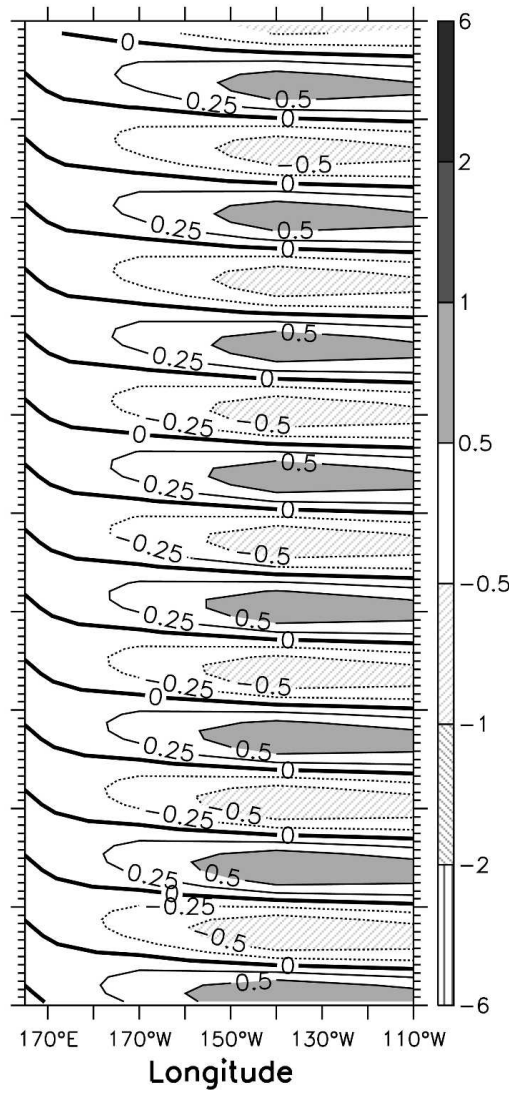

FIG. 14. (a) Sub-ENSO mode SST anomalies $\left({ }^{\circ} \mathrm{C}\right)$ as simulated by the ICM with the importance of zonal advection of SST decreased by $40 \%$ and vertical mixing and advection of SST increased by $40 \%$. (b) As in (a) except when no changes are made to the SST budget. (c) As in (a) except when the importance of zonal advection of SST is increased by $40 \%$ and vertical mixing and advection of SST decreased by $40 \%$. The sub-ENSO periods in (a), (b), and (c) are 18, 17, and 14 months, respectively. Shading and contours as in Fig. 1 c, with extra contours for \pm 0.25 .

SST variations. During this time it accounts for most of 1-2-yr anomalous variability (Fig. 1). After the 1997/98 El Niño event, it has a 14 month period and SST variations propagate westward. During this time it accounts for part of the near-annual anomalous variability (Fig. $1)$; a stronger annual cycle explains another part. Changes in the background state, via its modulation of terms in the SST budget, has been already proposed to explain the observed sub-ENSO mode changes (Jin et al. 2003; Kang et al. 2004). Results from ICM support this picture.

MSSA is heavily relied upon throughout this study. To test the robustness of our results we also performed principal oscillation pattern (POP) analysis (e.g., von Storch and Zweirs 1999) of both observed and modeled variability. In both cases, the sub-ENSO mode is identified in addition to ENSO. The spatial structure, temporal evolution, and relationship between ocean and atmospheric fields of the sub-ENSO mode are very similar to that revealed by our MSSA, and hence were not shown here. The existence of this second POP mode has previously been noted (Latif et al. 1993). Wavelet analysis of observed tropical variability also highlights the existence of the variability with a 1-2-yr time scale (Jin et al. 2003). We are thus confident that the sub-ENSO mode is not an artifact of the MSSA.

A summary of the answers our results provide for the three questions we posed follows: First, an independent mode of variability with a period of between 14 and 18 months does exist in the tropical Pacific. Second, the mode arises from the zonal-advective feedback, and may represent a destabilized Pacific basin mode. Third, its characteristics are controlled by the background state, via its influence on the anomalous SST budget.

Our study adds significant support to a growing body of work that indicates the slow ENSO, fast sub-ENSO, and annual cycle modes are the three major modes of the tropical coupled system. As already pointed out by 
Jin et al. (2003), the existence of a sub-ENSO mode of variability has significant implications for seasonal prediction. Apart from explaining previously classified "weak aborted" ENSO events, our results support Jin et al. (2003) suggestion that the co-occurrence of subENSO and ENSO events in 1997/98 contributed to the exceptional strength of the observed anomalies. A new aspect presented here is that there also appears to be a nonlinear interaction between ENSO and sub-ENSO.

Most of the current seasonal forecast skill arises from our ability to simulate and initialize ENSO-related variability. A clear gap exists in our ability to forecast subENSO variability. Why models have trouble forecasting this variability is not obvious, as they mostly include a complete representation of the ocean physics, and since the geostrophic ocean current anomalies, which are important for sub-ENSO, should be adequately initialized by heat content. Errors in model physics are one likely reason. ENSO and sub-ENSO modes depend on the relative importance of the thermocline and zonal-advective feedbacks, which is a very sensitive balance to achieve. Thus, it seems likely that advances in the prediction of sub-ENSO variability will require further progress on the reduction of the systematic errors in present models.

Acknowledgments. We thank Fei-Fei Jin and an anonymous reviewer for their useful comments. Use of freely available data from the TAO/TRITON array (http://www.pmel.noaa.gov/tao/) and from the Ocean Surface Currents Analyses-Real time (OSCAR) dataset (http://www.oscar.noaa.gov/index.html) is gratefully acknowledged. All MSSA and SSA were performed with the SSA-MTM tool kit, which was obtained from http://www.atmos.ucla.edu/tcd/ssa/. We are very grateful to Rong-Hua Zhang for providing the latest version of the ICM. This work was supported by the European projects ENSEMBLES (GOCE-CT-2003505539) and DYNAMITE (Contract 003903).

\section{REFERENCES}

Allen, M. R., and A. W. Robertson, 1996: Distinguishing modulated oscillations from coloured noise in multivariate datasets. Climate Dyn., 12, 775-784.

An, S. I., and F.-F. Jin, 2001: Collective role of thermocline and zonal advective feedbacks in the ENSO mode. J. Climate, 14, 3421-3432.

Barnett, T. P., M. Latif, N. Graham, M. Flugel, S. Pazan, and W. White, 1993: ENSO and ENSO-related predictability. Part I: Prediction of equatorial Pacific sea surface temperature with a hybrid coupled ocean-atmosphere model. J. Climate, 6, 1545-1566.

Battisti, D. S., and A. C. Hirst, 1989: Interannual variability in a tropical atmosphere-ocean model: Influence of the basic state, ocean geometry, and nonlinearity. J. Atmos. Sci., 46, $1687-1712$.

Bonjean, F., and G. S. E. Lagerloef, 2002: Diagnostic model and analysis of the surface currents in the tropical Pacific Ocean. J. Phys. Oceanogr., 32, 2938-2954.

Cane, M. A., and D. W. Moore, 1981: A note on low-frequency equatorial basin modes. J. Phys. Oceanogr., 11, 1578-1584.

Eckert, C., and M. Latif, 1997: Predictability of a stochastically forced hybrid coupled model of El Niño. J. Climate, 10, 14881504.

Federov, A. V., and S. G. Philander, 2001: A stability analysis of tropical ocean atmosphere interactions: Bridging measurements and theory for El Niño. J. Climate, 14, 3086-3101.

Ghil, M., and Coauthors, 2002: Advanced spectral methods for climatic time series. Rev. Geophys., 40, 1003, doi:10.1029/ 2000RG000092.

Goddard, L., and N. E. Graham, 1997: El Niño in the 1990s. $J$. Geophys. Res., 102, $10423-10436$.

Ji, M., A. Leetmaa, and V. E. Kousky, 1996: Coupled model predictions of ENSO during the 1980s and the 1990s at the National Centers for Environmental Prediction. J. Climate, 9, 3105-3120.

Jin, F.-F., 1997a: An equatorial ocean recharge paradigm for ENSO. Part I: Conceptual model. J. Atmos. Sci., 54, 811-829.

_ 1997b: An equatorial ocean recharge paradigm for ENSO. Part II: A stripped-down coupled model. J. Atmos. Sci., 54, 830-847.

_ , and J. D. Neelin, 1993: Modes of interannual tropical oceanatmosphere interaction-A unified view. Part I: Numerical results. J. Atmos. Sci., 50, 3477-3503.

— J.-S. Kug, S.-I. An, and I.-S. Kang, 2003: A near-coupled ocean-atmosphere mode in the equatorial Pacific Ocean. Geophys. Res. Lett., 30, 521-524.

Kang, I.-S., J.-S. Kug, S.-I. An, and F.-F. Jin, 2004: A near-annual Pacific Ocean basin mode. J. Climate, 17, 2478-2488.

Keenlyside, N. S., 2001: Improved modeling of zonal currents and SST in the tropical Pacific. Ph.D. thesis, Monash University, Clayton, Victoria, Australia, 194 pp.

— , and R. Kleeman, 2002: Annual cycle of equatorial zonal currents in the Pacific. J. Geophys. Res., 107, 3093, doi:10.1029/2000JC000711.

Kleeman, R., and A. M. Moore, 1997: A theory for the limitation of ENSO predictability due to stochastic atmospheric transients. J. Atmos. Sci., 54, 753-767.

Latif, M., A. Sterl, E. Maier-Reimer, and M. M. Junge, 1993: Climate variability in a coupled GCM. Part I: The tropical Pacific. J. Climate, 6, 5-21.

—- and Coauthors, 2001: ENSIP: The El Niño simulation intercomparison project. Climate Dyn., 18, 255-276.

Li, T., and S. G. H. Philander, 1996: On the annual cycle of the eastern equatorial Pacific. J. Climate, 9, 2986-2998.

McCreary, J. P., 1981: A linear stratified ocean model of the equatorial undercurrent. Philos. Trans. Roy. Soc. London, 298, 603-635.

McPhaden, M. J., and Coauthors, 1998: The Tropical OceanGlobal Atmosphere observing system: A decade of progress. J. Geophys. Res., 103, 14 169-14 240.

Meinen, C. S., and M. J. McPhaden, 2000: Observations of warm water volume changes in the equatorial Pacific and their relationship to El Niño and La Niña. J. Climate, 13, 3551-3559. Neelin, J. D., D. S. Battisti, A. C. Hirst, F.-F. Jin, Y. Wakata, T. 
Yamagata, and S. E. Zebiak, 1998: ENSO theory. J. Geophys. Res., 103, 14 261-14 290.

Schopf, P. S., and M. J. Suarez, 1988: Vacillations in a coupled ocean-atmosphere model. J. Atmos. Sci., 45, 549-566.

Syu, H.-H., and J. D. Neelin, 2000: ENSO in a hybrid coupled model, Part II: Prediction with piggyback data assimilation. Climate Dyn., 16, 35-48.

von Storch, H., and F. W. Zwiers, 1999: Statistical Analysis in Climate Research. Cambridge University Press, 484 pp.

Wu, R., and B. P. Kirtman, 2005: Near-annual SST variability in the equatorial Pacific in a coupled general circulation model. J. Climate, 18, 4454-4473.

Xie, S.-P., 1995: Interaction between the annual and interannual variations in the equatorial Pacific. J. Phys. Oceanogr., 25, 1930-1941.
Yu, X., and M. J. McPhaden, 1999: Seasonal variability in the equatorial Pacific. J. Phys. Oceanogr., 29, 925-947.

Zebiak, S. E., and M. A. Cane, 1987: A model El Niño-Southern Oscillation. Mon. Wea. Rev., 115, 2262-2278.

Zhang, R.-H., S. E. Zebiak, R. Kleeman, and N. Keenlyside, 2003: A new intermediate coupled model for El Niño simulation and prediction. Geophys. Res. Lett., 30, 2012, doi:10.1029/ 2003GL018010.

_, R. Kleeman, S. E. Zebiak, N. Keenlyside, and S. Raynaud, 2005a: An empirical parameterization of subsurface entrainment temperature for improved SST anomaly simulations in an intermediate ocean model. J. Climate, 18, 350-371.

- S. E. Zebiak, R. Kleeman, and N. Keenlyside, 2005b: Retrospective El Niño hindcasts/forecasts using an improved intermediate coupled model. Mon. Wea. Rev., 133, 2777-2802. 